\title{
A component-level methodology to evaluate the seismic repair costs of infills and services for Italian RC buildings
}

\author{
Maria Teresa De Risi ${ }^{1} \cdot$ Carlo Del Gaudio $^{1}$ (D) $\cdot$ Gerardo Mario Verderame ${ }^{1}$
}

Received: 11 April 2020 / Accepted: 25 August 2020 / Published online: 10 September 2020

(c) The Author(s) 2020

\begin{abstract}
The reliable estimation of seismic losses due to damage to buildings is paramount for the post-emergency management and the planning of recovery activities. For residential reinforced concrete (RC) infilled buildings, a significant role in the computation of seismic loss is played by non-structural components, above all infills, partitions and services, as shown in past earthquakes. In this work, a component-based methodology is proposed to assess seismic losses for residential RC buildings in Mediterranean region. The attention is focused on the repairing activities for masonry infills (typical enclosure or partitions elements in Italian and Mediterranean RC buildings), and for services (plumbing systems, electric equipment, floor/wall tiles...), commonly enclosed within the infill panels for the considered building typology. The described methodology can be used starting from the expected damage level to infills and partitions. It adopts given repair unit costs at different damage states of infills. The loss estimation methodology has been, first, validated by comparing predicted and actual repair costs for specific case-study buildings damaged by L'Aquila (Italy) 2009 earthquake. Then, the methodology has been applied to a wide dataset of RC buildings (about 2500 residential buildings) damaged by L'Aquila earthquake available from the literature, to show its possible application at a large-scale level. A good agreement between observed and predicted costs is obtained both for specific case-study buildings and for the wider building stock, especially when damage to structural components is very limited.
\end{abstract}

Keywords RC building $\cdot$ Masonry infill and partition - Damage assessment $\cdot$ Postearthquake survey $\cdot$ Seismic repair cost $\cdot$ L'Aquila earthquake

Maria Teresa De Risi: beneficiary of an AXA Postdoctoral Research Fund.

Carlo Del Gaudio

carlo.delgaudio@unina.it

Maria Teresa De Risi

mariateresa.derisi@unina.it

Gerardo Mario Verderame

verderam@unina.it

1 Department of Structures for Engineering and Architecture, University of Naples Federico II, via Claudio 21, 80125 Naples, Italy 


\section{Introduction}

The high seismicity, combined with the significant exposure, makes Italy one of the countries where the consequences of earthquakes are more devastating than elsewhere. Dolce et al. (2019a) estimate that the earthquakes with magnitude between 5.5 and 6.9, occurred in Italy from 1976 to 2012, caused monetary losses for over $€ 150$ billion, due to recovery and reconstruction costs. In addition, Italian buildings inventory is characterized by strong deficiencies, being generally constructed before the enacting of seismic codes. Similar issues should be face up in many other seismic prone areas in the Mediterranean region and worldwide.

Seismic vulnerability represents the only factor that can be reasonably used to mitigate the effects of earthquakes though planning strategies of intervention for risk reduction at regional/national scale. To this end, the estimation of repair costs after seismic events can be paramount in defining the feasibility and/or the convenience of public incentives plans for seismic risk mitigation (Cosenza et al. 2018). Additionally, costs associated with natural hazards that can occur during the service lifetime should be properly considered in life-cycle cost assessment, in the design and management of infrastructures or buildings portfolio (Chang and Shinozuka 1996; Kang and Wen 2000; Jalayer et al. 2011; Li et al. 2020).

Different methods for loss assessment have been developed in the last fourty years in the literature. Some of them assess losses starting from damage at "building level", by using empirical Damage Probability Matrix (DPM) or empirical/analytical fragility curves (Rossetto and Elnashai 2003; Gautam et al. 2018; Del Gaudio et al. 2017, 2019a; Rosti et al. 2019b, among many others). Other approaches estimate losses at component level, starting from (quite recent) studies from the literature that have addressed the definition of DPM or fragility curves at a (structural- or nonstructural-) component level (e.g., Aslani and Miranda 2005; Pagni and Lowes 2006; ATC 58 2012a, b; Del Gaudio et al. 2019b, among others), sometimes empirically relating the intensity measure due to a seismic scenario to the damage suffered by specific building components (Del Gaudio et al. 2017; Adhikari and Gautam 2019).

The first loss estimation approaches from the literature (Guagenti et al. 1988; Yang et al. 1989; Colonna et al. 1994; Bramerini et al. 1995; Di Pasquale and Orsini 1998) evaluate expected annual losses from the probabilistic convolution of hazard and vulnerability. Differences among the mentioned evaluations regarded: (1) the way of assessing seismic hazard; and (2) the way of characterizing vulnerability, by means of DPMs and damage factor (DF) (equal to the ratio between repair cost and the complete replacement cost, for different damage levels at building level). Later, Di Pasquale et al. (2005) provided a refinement and extension of the previous methods. They developed a "probabilistic" method that returns the complete risk probability curves for four buildings typologies and for the whole dwellings population in Italy considering all the events occurring in a time period.

In Crowley et al. (2008) and Bal et al. (2008) seismic loss assessment was performed by means of the DBELA method (Crowley et al. 2004) to characterize the vulnerability. In Crowley et al. (2008), the mean damage ratio related to reinforced concrete (RC) buildings of 150 municipalities of Marmara Region is evaluated using the Boore (1997) ground-motion prediction equation related to a given scenario earthquake and DF based on HAZUS (FEMA 2003) suggestions. In Bal et al. (2008), social losses (injuries and deaths) are evaluated for a huge building stock located in the northern Marmara region 
(made up of both RC and masonry structures) for a scenario involving the rupture of the Main Marmara Fault close to Istanbul in a Mw 7.5 earthquake through the use of the model proposed by Spence (2007).

Recently, Silva et al. (2018), Dolce et al. (2019b) and Rosti et al. (2019a) developed seismic risk maps for Italy reporting the average annual loss due to ground shaking through the use of fragility curves for building "classes". In Silva et al. (2018), fragility curves developed by Borzi et al. (2008) and Ahmad et al. (2010) were used. In Dolce et al. (2019b), fragility curves derived by a delegation of the scientific engineering community (Eucentre-European Centre for Training and Research in Earthquake Engineering — and ReLUIS-Laboratories University Network of seismic engineering) were adopted. In Rosti et al. (2019a), fragility curves empirically derived for residential masonry (Rosti et al. 2019b) and RC buildings (Del Gaudio et al. 2019a) were applied.

On the other hand, a new generation of methods developed in the context of FEMA P-58 (ATC 58 2012a, b) approach. They proposed the estimation of seismic losses as the sum of the contribution of each involved component, thus, requiring the use of fragility functions and consequence data for each component separately. In FEMA P-58, the Performance Assessment Calculation Tool (PACT) was introduced, integrating the results of structural analysis with a wide repository of fragility and consequence functions for a broad selection of components. In O'Reilly and Sullivan (2018) and Del Vecchio et al. (2018), PACT procedure was adapted to the Italian building stock. In both cases, an upgrade of fragility database for components typical of the Mediterranean area, such as masonry infills, is carried out. In O'Reilly and Sullivan (2018), loss assessment of Italian RC frame buildings with masonry infills was pursued. In Del Vecchio et al. (2018), predicted repair costs evaluated for five case study RC buildings damaged after L'Aquila (2009) Earthquake found good agreement with actual costs, available from funding requests, both at building level and at component level (infills and partitions, structural subassemblies, floor finishes, and other acceleration sensitive, non-structural components).

Moreover, some methods provided a compromise between the rigour of a componentbased approach and the simplicity of an approach based on global damage at the building level, introducing some simplifications in the loss estimation procedure. In Ramirez (2009), the introduction of relationships between structural response and repair cost for each story allows the simplification of the PEER's framework (Aslani and Miranda 2005). As a matter of fact, Ramirez (2009) derived pre-elaborating specific fragility functions for components of each storey and the corresponding repair costs. These relationships were also used in Welch et al. (2014) within a loss assessment procedure using the Direct Displacement-Based Assessment procedure, adapted from Sullivan and Calvi (2011), incorporating also uncertainties in seismic capacity and demand. Furthermore, a simplified approach was developed in Perrone et al. (2019) to evaluate the Expected Annual Loss (EAL) of RC buildings using the results of structural analyses and a closed-form expression, arising from the assumptions of: (1) linearity between the repair costs and seismic intensity, and (2) of linear approximation of the hazard curve in log-log space.

Lately, several methods (De Martino et al. 2017; Del Vecchio et al. 2019) have developed to empirically relate repair cost information from funding requests and damage to buildings subjected to post-earthquake inspections after recent events occurred in Italy. In De Martino et al. (2017), a database of 1500 RC and 1000 masonry buildings damaged after the 2009 L'Aquila earthquake have been deeply analysed. The Authors provided the actual repair costs for the investigated real buildings (obtained by the actual projects performed by practitioners involved in the reconstruction process in the aftermath of the seismic event), depending on their post-earthquake usability judgment. 
Based on such data, they also proposed an empirical correlation between the actual building repair costs and their post-earthquake observed damage. In Del Vecchio et al. (2019) a smaller dataset (120) of RC buildings has been used to analyse in detail the correlation between actual repair costs and observed damage both at building level and at component level, emphasizing the strong contribution given by hollow clay brick infills and partitions in the overall repair cost estimation.

Even though infills and services generally represented the most significant portion of economic losses due to earthquakes (Dolce and Goretti 2015; Del Gaudio et al. 2016; Del Vecchio et al. 2019), especially in the Mediterranean area, they have been specifically considered in loss estimation approaches in the literature only very recently. As a result, a careful estimation of all the required repairing activities for infills/partitions and related services is still necessary and crucial to predict the expected seismic losses for $\mathrm{RC}$ buildings in a reliable way.

\subsection{Research significance}

Several studies in the literature analysed damage to buildings or infrastructures due to the last seismic events (1981 Irpinia (Italy), 1994 Northridge (USA), 2009 L’Aquila (Italy), 2011 Lorca (Spain), 2015 Gorka (Nepal), 2016 Centre Italy). More in detail, about RC buildings, typical detected "deficiencies" are represented by: lack of sufficient reinforcement in columns, presence of squat columns leading to brittle failure, lack of confinement in columns, insufficient overlap of reinforcement, strong beam/weak column hierarchy, beam-to-column joint failure (e.g., Ricci et al. 2011; Gautam and Chaulagain 2016; Ruiz-Pinilla et al. 2016, among many others). The presence of infills, particularly in residential RC buildings, can further emphasize some of these structural deficiencies, and often being responsible for significant damage (Stratta and National Research Council 1981; Ricci et al. 2011; De Luca et al. 2014; Gautam and Chaulagain 2016; Del Gaudio et al. 2017; Furtado and De Risi 2020) and resultant direct losses (De Risi et al. 2019).

Despite the very significant number of studies that highlight existing structural or nonstructural deficiencies and resulting damage due to historical earthquakes, in very few cases researchers were able to explicitly quantify the loss contribution of each damage component to the total losses due to a seismic event. This is particularly true for nonstructural components like infills and services (Taghavi and Miranda 2003; De Risi et al. 2019; Del Vecchio et al. 2019). L'Aquila earthquake represented a unique opportunity of analysis of actual data, since, in the aftermath of the event, official statistical data about actual repair costs have been collected by analysing the technical and financial information that technicians submitted to the government for approval procedure for funding aids (Dolce and Manfredi 2015; De Martino et al. 2017; Di Ludovico et al. $2017 \mathrm{a}, \mathrm{b})$. Some of these studies started highlighting that the percentage influence of infills and services on the total repair cost was significant, and, thus, worthy to be investigated and duly considered, as addressed in the present work.

In this research work, a component-based methodology to assess seismic losses for typical Italian and Mediterranean residential RC buildings is proposed. A specific focus for such estimation is addressed to:

- masonry infills, typical enclosure or partitions elements in RC buildings, and

- services, like plumbing systems or electric equipment. 
For the investigated buildings typology, services are generally allocated within the infill panels (such as electric equipment or heating hot water piping), thus making the refurbishment of the former strictly related to damage suffered by the latter. This assumption allows avoiding the use of component fragility functions specifically derived for services, and simply using fragility functions for infill panels to determine damage to both infills and services. Obviously, this simplification makes the loss estimation procedure proposed herein particularly suitable for RC buildings with bricks masonry infills where this hypothesis is fulfilled, which overall represent the great majority of the residential RC buildings in the Mediterranean area. On the contrary, different approaches should be used if services are allocated elsewhere, for example within suspended ceilings, requiring the use of specific fragility functions.

The loss estimation methodology described herein allows predicting repair costs starting from the expected damage level to infills and partitions, both predicted by means of numerical tools or directly obtained by post-earthquake in situ surveys. Repair costs are determined through a detailed list of repairing activities, unit costs, and area of intervention for different damage states (DSs), coherently with the EMS-98 (Grunthal 1998) macro-seismic scale.

The proposed methodology is validated, first, by means of the comparison with actual repair costs related to some case-study buildings damaged after L'Aquila (Italy) 2009 earthquake, based on post-earthquake observed damage. Then, the same procedure is applied to a wide dataset of RC buildings (about 2500), coming from the same post-earthquake dataset. The good agreement between actual and predicted repair costs, both for specific casestudy buildings and for a wider building dataset, provides a promising validation of the proposed loss estimation procedure and its potential for large scale applications.

\section{Damage states definition for infills and partitions}

In the past, several researchers analysed how define DSs of RC buildings (e.g., Grunthal 1998; Baggio et al. 2007), and qualitative and quantitative described the severity and the extent of cracking patterns involving structural and non-structural components for each DS. Some of them dealt with the definition of DSs specifically for non-structural elements, as infills and partitions (Cardone and Perrone 2015; Sassun et al. 2016; Del Gaudio et al. $2019 \mathrm{~b}$ ), the main focus of this research work. In this section, DSs definitions according to Grunthal (1998) and Baggio et al. (2007) are reported and compared, since they will be later adopted in the following sections and since they represent the main reference for the more recent studies about this topic (Cardone and Perrone 2015; Sassun et al. 2016; Del Gaudio et al. 2019b).

First, EMS-98 (Grunthal 1998) defined five DSs for earthquake-damaged buildings. For RC buildings, three of them were specifically dedicated to damage to infills and partitions, as shown in Table 1; the last two DSs were related to damage to RC elements only, in the hypothesis that, beyond DS3, infills have already collapsed. DS1, DS2, and DS3 according to EMS-98 (Grunthal 1998) basically differ to each other depending on the severity and the extent of cracks in partitions and infills, from "slight" to "heavy" damage, as reported in Table 1 . 
Table 1 Relationship between DSs defined by Grunthal (1998) and Baggio et al. (2007)

\begin{tabular}{llll}
\hline EMS-98 (Grunthal 1998) & Baggio et al. (2007) & \\
\hline DS0 & No damage & D0-Null damage & DE \\
DS1 & Negligible-slight damage: & D1: slight damage & $<1 / 3$ \\
& Fine cracks in partitions and infills & & $1 / 3-2 / 3$ \\
& & & $>2 / 3$ \\
DS2 & Moderate damage: & D2-D3: medium-severe damage & $<1 / 3$ \\
& Cracks in partition and infill walls & & $1 / 3-2 / 3$ \\
& & & $>2 / 3$ \\
DS3 & Substantial-heavy damage: & D4-D5: very heavy damage & $<1 / 3$ \\
& Large cracks in partition and infill walls, & & $1 / 3-2 / 3$ \\
& failure of individual infill panels & & $>2 / 3$ \\
\hline
\end{tabular}

Baggio et al. (2007) later proposed a more detailed (and quantitative) description of DSs for buildings, analyzing damage to vertical structures, floors, stairs, roofs and infills. Three damage grades were identified by Baggio et al. (2007): "D1"or Slight", "D2-D3" or Medium-Severe", and "D4-D5" or "Very heavy". About infills and partitions, "D1" and "D2-D3" are associated to cracks in infills less than $1 \mathrm{~mm}$ and from-1-to-5 mm width, respectively. Localised bricks expulsions can be found in "D2-D3". "D4-D5" is related to a partial or total collapse of the infill panel. A damage extent (DE) was also coupled with the damage severity. Three "ranges" of DE are identified in Baggio et al. (2007): less than $1 / 3$ of the elements of the building; between $1 / 3$ and $2 / 3$ of all the buildings' elements and more than $2 / 3$ of the building's elements, (see Table 1 ).

Based on these remarks, the correspondence between EMS-98 and Baggio et al. (2007) is reported in Table 1.

\section{Proposed procedure to evaluate repair cost of infills and services}

In this section the proposed methodology to evaluate Total Repair Cost (TRC) for RC buildings, considering infills and services, is described. The methodology presented herein belongs to the so-called "component-level" loss prediction procedures, similarly to Performance Assessment Calculation Tool (PACT) for probabilistic assessment of losses reported in FEMA P-58 (ATC 58. 2012a, b). As mentioned in Sect. 1, the PACT method starts from the results of a structural analysis. Then structural damage and economic losses are evaluated combining the analysis results with fragility functions and consequence data for a wide repository of structural and non-structural components. Unfortunately, no specific data (neither fragility functions or repair costs) related to infilled RC moment resisting frame buildings, widely used in Mediterranean area, are accounted for in the PACT tool (Cardone and Perrone 2015; Del Vecchio et al. 2018). The methodology presented herein aims to fill this gap, and to evaluate TRC for infilled RC buildings by using data specifically derived for this building typology. Only information about damage on infills/ partitions are considered, being significant their contribution on damage analysis for the specific investigated structural typology, as highlighted by recent studies on this topic (Taghavi and Miranda 2003; Dolce and Goretti 2015; Del Gaudio et al. 2016; Del Vecchio et al. 2019). The information about damage on infills/partitions is thus used to evaluate the 
repair costs due to the main repair activities for refurbishment of infills, partitions and for all services allocated in within, whose sum for all the components of the building provide its total repair costs. In fact, for residential Italian and Mediterranean RC buildings infilled with hollow clay bricks the repair costs for services can be related to damage of masonry panels, since the former are commonly located within the latter or closely interacting with them.

For the application of the loss estimation procedure, damage classification according to EMS-98 definition should be first performed (see Sect. 2). Then, repair costs due to infills (Sect. 3.1) and services (Sect. 3.2) should be evaluated. Thus, total repair costs due to both infill panels and services can be computed as a function of damage suffered by infills, as shown in Sect. 3.3.

\subsection{Repair cost for infills and partitions}

First, repair costs for infills and partitions have to be determined. To this aim, a list of elementary actions to be performed for a given DS is fixed, determining the main operations required to repair infills/partitions. Then, the repair cost at each $\mathrm{DS}_{\mathrm{i}}$ (with $\mathrm{i}=1,2,3$ ) can be calculated by summing up the products of all the unit costs $\left(c_{j}\right)$ for each elementary action multiplied by the relevant area of intervention $\left(\mathrm{A}_{\mathrm{j}, \mathrm{DSi}}\right)$. In what follows, the Price List of Public Works in Abruzzi Region (B.U.R.A. 2017) has been used to define such unit costs, coherently with the validation of the methodology later shown in Sects. 4 and 5. Anyway, every other definitions of unit costs can be used for other applications.

Table 2 reports both the unit costs $\left(c_{j}\right)$ and the relevant area of intervention $\left(\mathrm{A}_{\mathrm{j}, \mathrm{DSi}}\right)$ considering seven different activity groups (from " $a$ " to " $g$ ") and the specific elementary actions required for each of them.

Double leaf cavity masonry walls representative of typical existing RC infilled buildings in the Mediterranean area are considered in this study. They are assumed as constituted by $(12 \times 25 \times 25) \mathrm{cm}$ hollow clay bricks (with a void percentage $>55 \%)$ for exterior leaf, and $(8 \times 25 \times 25) \mathrm{cm}$ hollow clay bricks (with a void percentage $>55 \%)$ for interior leaf, with thermal insulation, as typical of the Mediterranean area (Bal et al. 2008). This assumption is also valid for RC buildings struck by L'Aquila (2009) earthquake (Ricci et al. 2011) that will be analysed in next sections. The repair cost $\left(\overline{\mathrm{C}}_{\mathrm{DSi}}^{\text {Infills }}\right)$ for this panel typology-hereinafter referred to (hollow + hollow) panel—at the damage state $\mathrm{DS}_{\mathrm{i}}$, can be evaluated as shown in Eq. (1):

$$
\overline{\mathrm{C}}_{\mathrm{DSi}}^{\text {Infills }}=\sum_{\mathrm{j}}^{\{\mathrm{a}, \mathrm{b}, \mathrm{c}, \mathrm{d}, \mathrm{e}, \mathrm{f}, \mathrm{g}\}}\left(\mathrm{c}_{\mathrm{j}} \cdot \mathrm{A}_{\mathrm{j}, \mathrm{DSi}}\right)
$$

Note that $\mathrm{c}_{\mathrm{j}}$ and $\mathrm{A}_{\mathrm{j}, \mathrm{DSi}}$ reported in Table 2 descend from those reported in Del Gaudio et al. (2019b) with some modifications. Firstly, only three DSs are considered herein, i.e., those related respectively to the light cracking damage pattern, the extensive cracking damage pattern, the total infill collapselfailure condition (Del Gaudio et al. 2019b). Thus, the damage state related to the "economically convenience" limit to repair without demolish/ reconstruct has been discarded in this work, since it differs from the total infill collapsel failure condition only for what concern the inter-story drift ratio (IDR) capacity, being substantially equal the corresponding $\mathrm{c}_{\mathrm{j}}$ and $\mathrm{A}_{\mathrm{j}, \mathrm{DSi}}$. Moreover, the repairing actions related to removal of solid wood frame, box and roller shutter and installation of old window or door 


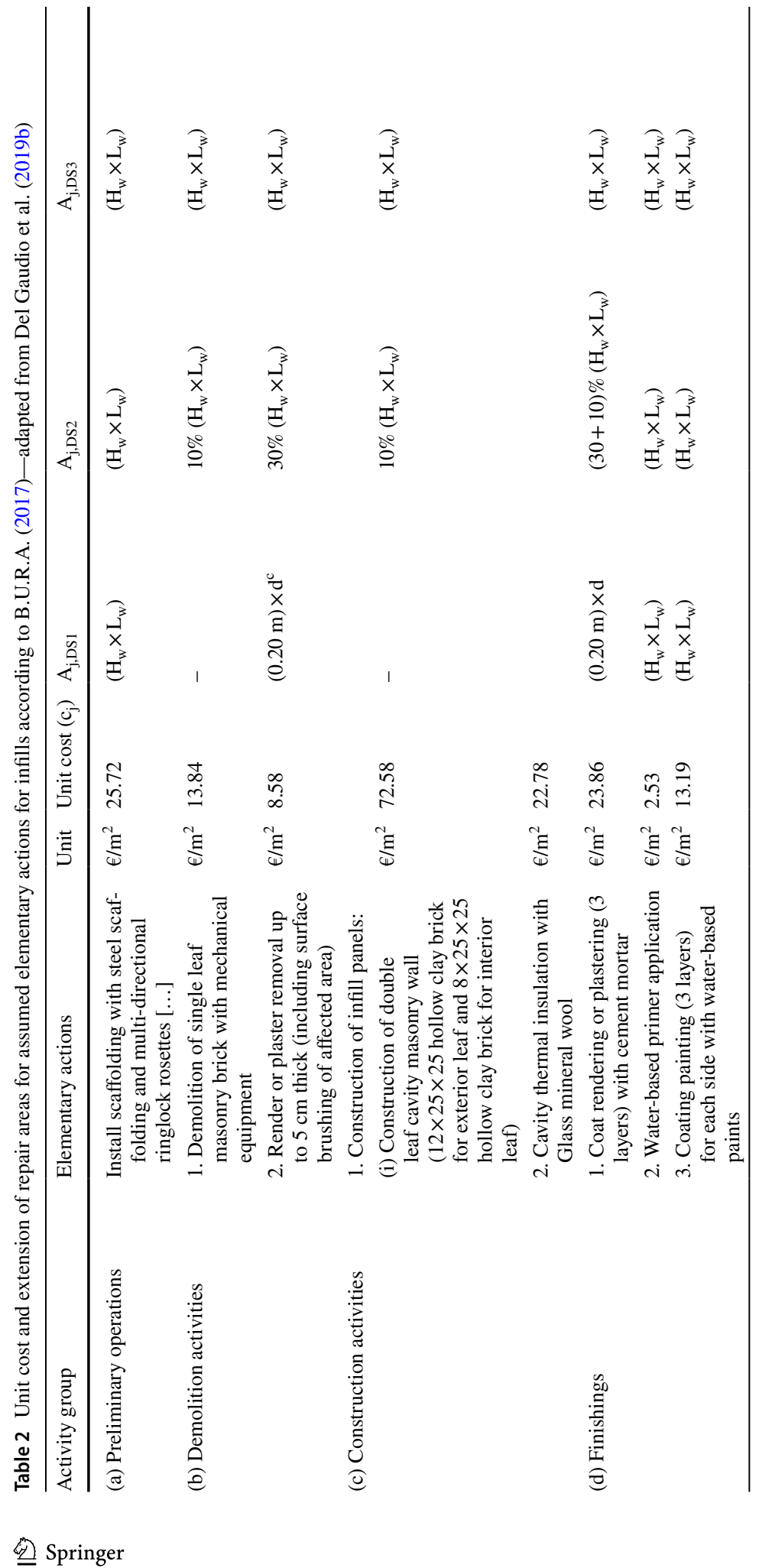




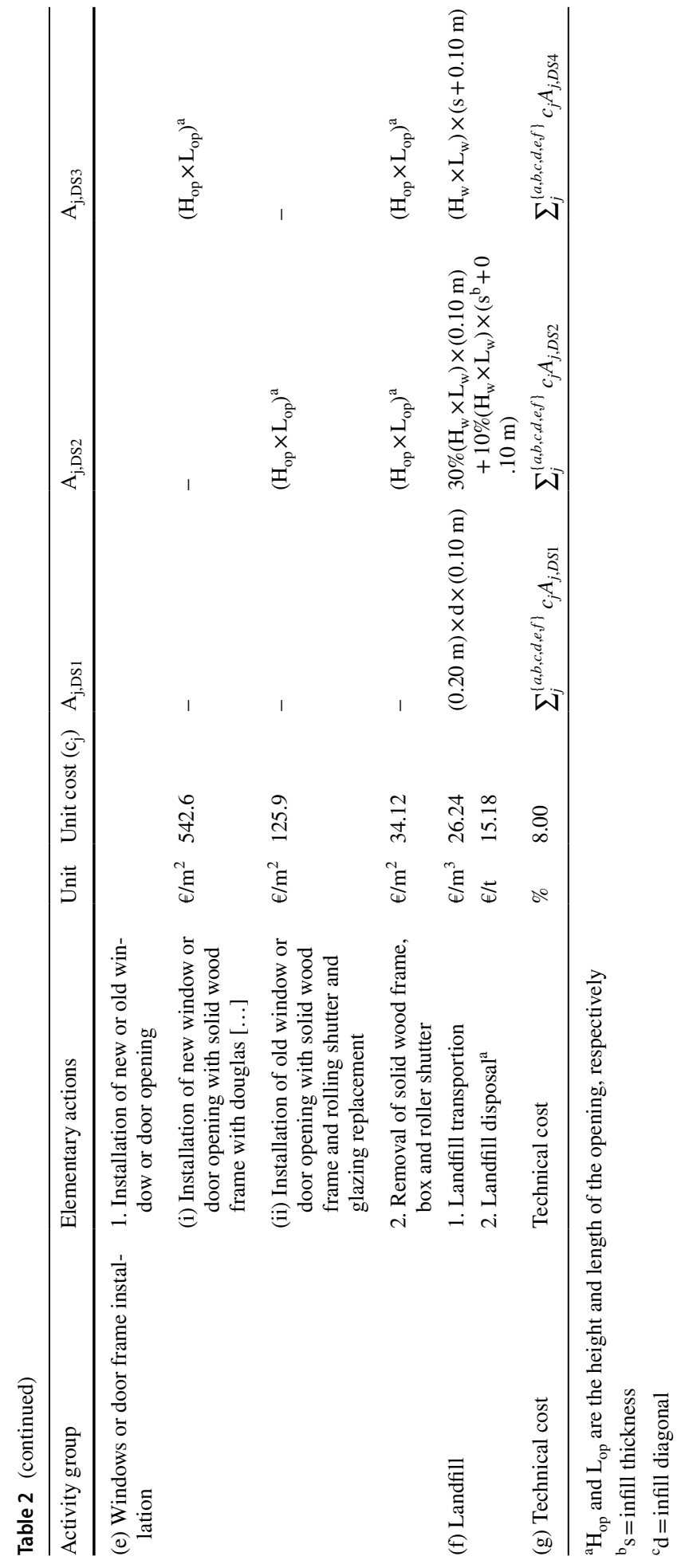


Table 3 Repair costs for double leaf hollow clay bricks $\left(\overline{\mathbf{C}}_{\mathrm{DSi}}^{\text {Infills }}\right.$ per infill surface unit (obtained from the application of unit costs and extension relative to the activity groups of Table 2)

\begin{tabular}{llll}
\hline & $\overline{\mathrm{C}}_{\mathrm{DS} 1}^{\text {Infills }}\left(€ / \mathrm{m}^{2}\right)$ & $\overline{\mathrm{C}}_{\mathrm{DS} 2}^{\text {Infills }}\left(€ / \mathrm{m}^{2}\right)$ & $\overline{\mathrm{C}}_{\mathrm{DS} 3}^{\text {Infills }}\left(€ / \mathrm{m}^{2}\right)$ \\
\hline Solid panel & 77.0 & 105.3 & 285.8 \\
Panel with window & 73.0 & 118.76 & 331.4 \\
Panel with door & 69.2 & 131.55 & 374.9 \\
\hline
\end{tabular}

opening with solid wood frame and rolling shutter and glazing replacement are included herein, according to suggestions reported in Del Vecchio et al. (2019).

Hence, $\overline{\mathrm{C}}_{\mathrm{DSi}}^{\text {Infills }}$ has been evaluated for three panel typologies: "solid" (i.e., without openings), "with window opening" and "with door opening", following a Monte Carlo simulation technique, considering a number of realizations $(\mathrm{N}=1000)$ varying the infill dimensions in typical ranges. Therefore, infill length, $\mathrm{L}_{\mathrm{w}}$, is assumed to vary from 4.00 to $5.00 \mathrm{~m}$; the infill height is assumed, on average, equal to $\mathrm{H}_{\mathrm{w}}=2.75 \mathrm{~m}$; openings are considered as constituted by wood frames with dimensions of $(0.90 \times 1.50) \mathrm{m}^{2}$ or $(1.20 \times 2.20) \mathrm{m}^{2}$ for window or door opening, respectively.

As a result, the repair cost $\bar{C}_{D S i}^{\text {Infills }}$ for each panel typology at $\operatorname{DS}_{i}(i=1, \ldots, 3)$ are reported in Table 3. A dispersion around these values may be considered due to variability related to different professional practices or to different unit costs in different geographical areas or considering uncertainty in contractor pricing strategies. However, this aspect is not considered herein and does not limit the presented methodology.

Additionally, it has been assumed that interior infill partitions are made up of $(8 \times 25 \times 25) \mathrm{cm}$ hollow clay bricks with cement mortar. The corresponding repair costs, $\overline{\mathrm{C}}_{\mathrm{DSi}}^{\mathrm{Partitions}}$, for different damage states are evaluated starting from those of (hollow + hollow) clay brick panel, $\overline{\mathrm{C}}_{\mathrm{DSi}}^{\text {Infils }}$, by simply subtracting/adding some specific activities as reported in Table 4.

Repair costs related to infills and partitions provided in Tables 3 and 4 are specific costs for infill panel surface unit. However, a very useful information for more rapid loss estimations certainly is the knowledge of repair costs of infills and partitions (IP) per floor surface unit $\left(\mathrm{C}_{\mathrm{DSi}}^{\mathrm{IP}}\right)$. Obviously, $\mathrm{C}_{\mathrm{DSi}}^{\mathrm{IP}}$ depends on the ratio between total infill surface area at each floor and the floor plan area (A) and should be determined caseby-case. To overcome this case-specific limitation, herein a Montecarlo simulation is applied with $\mathrm{N}=1000$ simulations, assuming some hypotheses, quite common in existing RC infilled buildings, based on the analysis of data presented in the following applications (discussed in Sect. 5):

- the floor Plan Ratio (PR), i.e., longitudinal side $\left(\mathrm{L}_{\mathrm{x}}\right)$-to-transverse side $\left(\mathrm{L}_{\mathrm{y}}\right)$ ratio, can vary between 1 and 2.5 (with a uniform probability distribution) (Del Gaudio et al. 2017);

- plan area (A) varies within the range $[70 ; 250] \mathrm{m}^{2}$ with a uniform probability distribution;

- The presence of openings is assumed as a uniform discrete RV among the cases "solid" panel, panel "with window opening" and panel "with door opening";

- The total linear length of interior partitions $\left(\mathrm{L}_{\mathrm{int}, \mathrm{x}}\right.$ and $\left.\mathrm{L}_{\mathrm{int}, \mathrm{y}}\right)$ along the two main orthogonal directions ( $\mathrm{x}$ and $\mathrm{y}$ ) of the building is obtained in the hypothesis that the geometric percentage of interior infills was equal to the $50 \%$ of the geometric percentage of exterior infills (as suggested in Bal et al. 2008; Del Gaudio et al. 2017). It is also assumed that the thickness of external ( $\mathrm{t}_{\mathrm{w}}^{\text {Infills }}$ ) and interior ( $\mathrm{t}_{\mathrm{w}}^{\text {Partitions }}$ ) infill panels are equal to 200 and $80 \mathrm{~mm}$, respectively. 


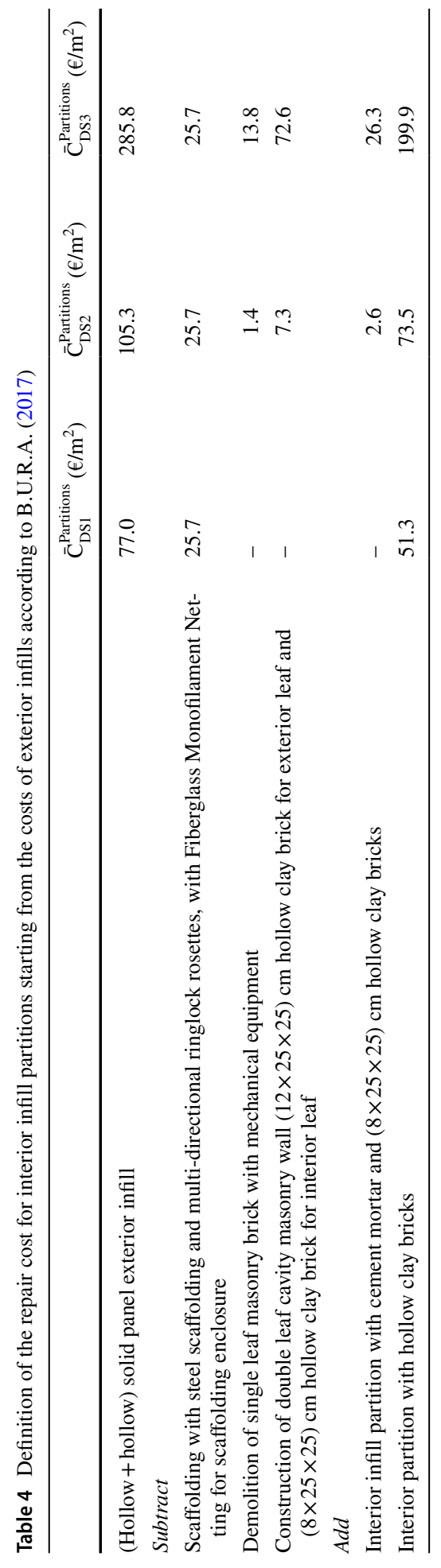


Given these hypotheses, the exposed infill area per each floor $\left(\mathrm{S}_{\text {Infills }}^{\prime}\right)$ and the exposed partition area per each floor $\left(\mathrm{S}_{\text {Partitions }}^{\prime}\right)$, can be evaluated as in Eqs. (2a) and (2b):

$$
\begin{gathered}
\mathrm{S}_{\text {Infills }}^{\prime}=2 \cdot\left(\mathrm{L}_{\mathrm{x}}+\mathrm{L}_{\mathrm{y}}\right) \cdot \mathrm{h} \\
\mathrm{S}_{\text {Partitions }}^{\prime}=\left(\mathrm{L}_{\mathrm{x}}+\mathrm{L}_{\mathrm{y}}\right) \cdot \mathrm{h} \cdot \mathrm{t}_{\mathrm{w}}^{\text {Infills }} / \mathrm{t}_{\mathrm{w}}^{\text {Partitions }}
\end{gathered}
$$

where $\mathrm{L}_{\mathrm{x}}, \mathrm{L}_{\mathrm{y}}, \mathrm{t}_{\mathrm{w}}^{\text {Infills }}$, and $\mathrm{t}_{\mathrm{w}}^{\text {Partitions }}$ have been defined above, and $h$ is the inter-story height. Thus, if the whole exposed infill area in a given storey is characterised by damage $\mathrm{DS}_{\mathrm{i}}$ (with $\mathrm{i}=1,2,3$ ), $\mathrm{C}_{\mathrm{DSi}}^{\mathrm{IP}}$ can be calculated as in Eq. (3). Mean, 50th (median), 16th, and 84th percentiles (prctile) of costs $\mathrm{C}_{\mathrm{DSi}}^{\mathrm{IP}}$ obtained in such a way are reported in Table 5, along with their standard deviation (std).

$$
\mathrm{C}_{\mathrm{DSi}}^{\mathrm{IP}}=\frac{\overline{\mathrm{C}}_{\mathrm{DSi}}^{\text {Infills }} \cdot \mathrm{S}_{\text {Infills }}^{\prime}+\overline{\mathrm{C}}_{\mathrm{DSi}}^{\text {Partitions }} \cdot \mathrm{S}_{\text {Partitions }}^{\prime}}{\mathrm{A}}
$$

\subsection{Repair cost for Services}

Repair costs for services are determined, considering four different activity groups, namely: (1) plumbing and (2) electrical systems, (3) radiators and (4) roof/wall tiles. As for infills/ partitions, the Price List of Public Works in Abruzzi Region (B.U.R.A. 2017) was used also for services. Moreover, the corresponding costs for technicians and those for landfill transportation and disposal are also considered.

As anticipated before, repair activities for services have been associated to damage suffered by infill panels, since services are generally allocated within infills in residential RC buildings in the Mediterranean region. Therefore, it is assumed herein that if infills are characterized by several diagonal cracks for an extensive panel area (DS2), some water pipes of distribution systems could break or some of sanitary equipment could crack, thus requiring their refurbishment. In addition, the restoration of water and/or wastewater distribution system requires the removal of old floor/wall tiles, the installation of screed layer, the supplying and installation of floor/wall tiles for bathroom. Obviously, if infill panels completely collapse (DS3), all services (partially or totally) allocated in within, namely plumbing and electrical systems, and radiators, have to be re-installed after the construction of the new infill panels. Moreover, it is also assumed that the collapse of infills could produce cracks in the floor tiles requiring their removal, along with the screed layer, their supplying and re-installation.

Table 5 Repair costs for infills and partitions per plan surface unit

\begin{tabular}{llll}
\hline Infills + partitions & $\mathrm{C}_{\mathrm{DS} 1}^{\mathrm{IP}}\left(€ / \mathrm{m}^{2}\right)$ & $\mathrm{C}_{\mathrm{DS} 2}^{\mathrm{IP}}\left(€ / \mathrm{m}^{2}\right)$ & $\mathrm{C}_{\mathrm{DS} 3}^{\mathrm{IP}}\left(€ / \mathrm{m}^{2}\right)$ \\
\hline Mean & 142.1 & 224.1 & 485.5 \\
Median & 135.0 & 213.1 & 462.8 \\
16th prctile & 102.8 & 156.2 & 325.8 \\
84th prctile & 105.7 & 159.5 & 332.7 \\
Std & 26.6 & 43.4 & 98.8 \\
\hline
\end{tabular}




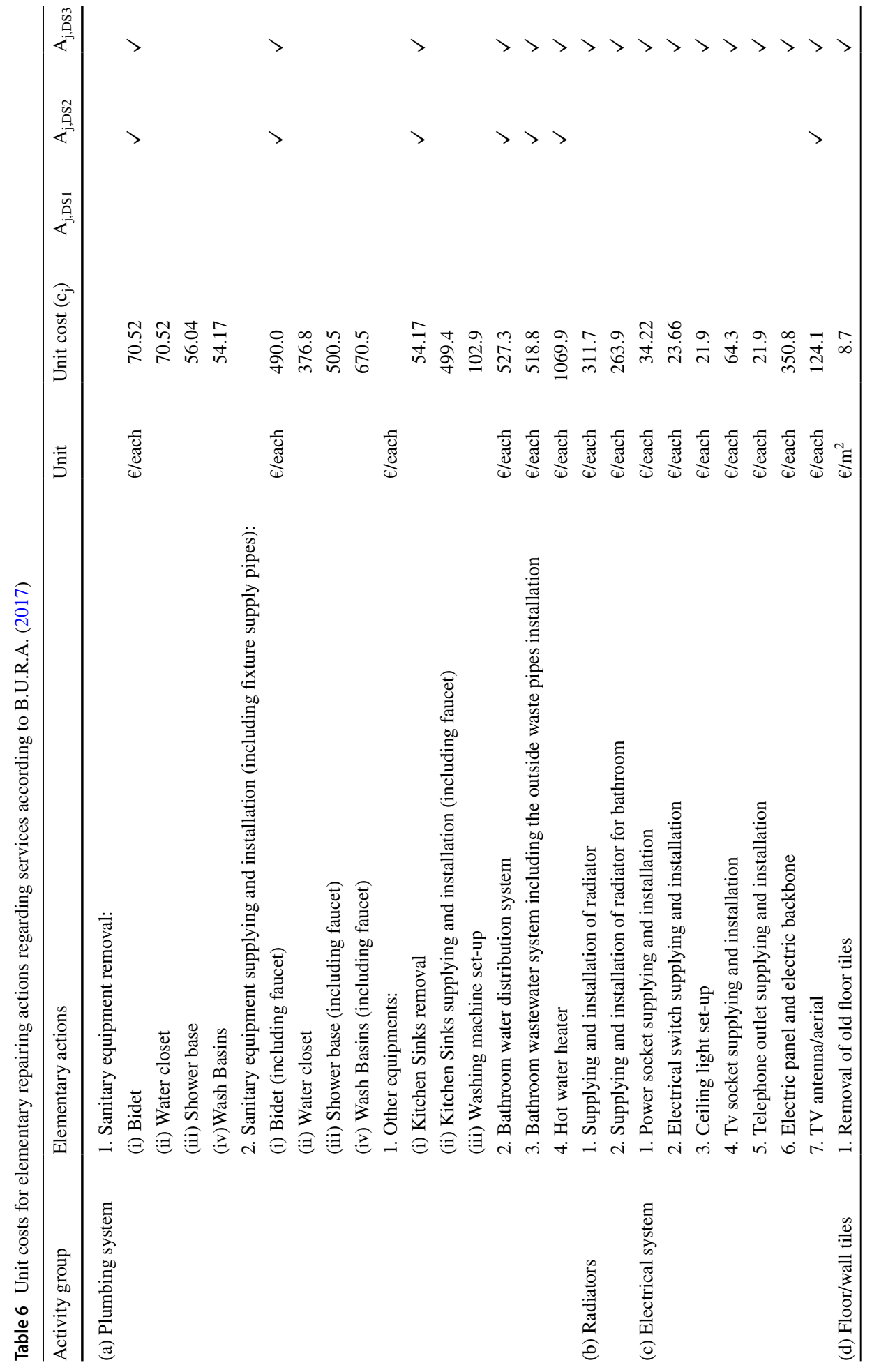




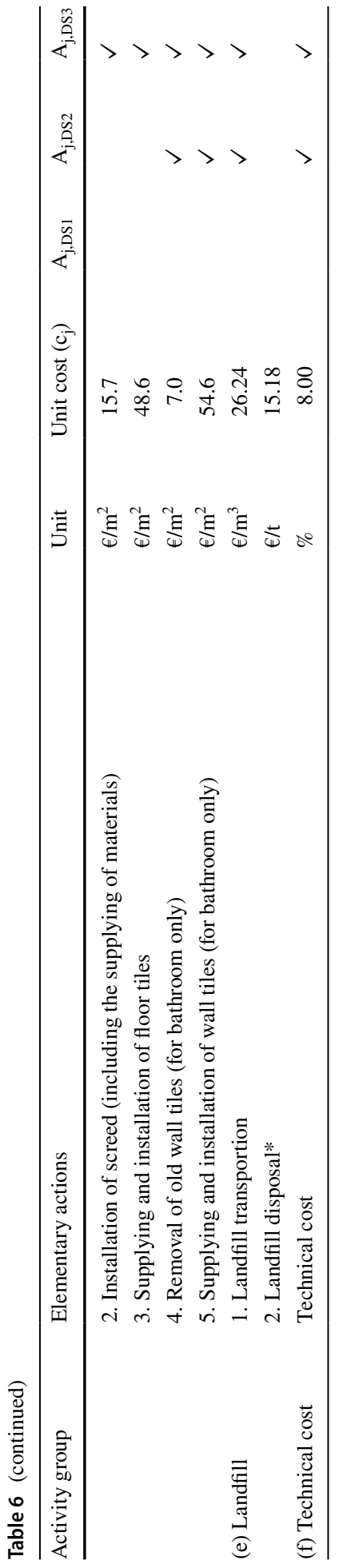


The association between the repair activities for services and infills DSs is reported in Table 6 (5th to 7 th columns), along with the unit costs for each required elementary action evaluated from B.U.R.A. (2017).

Generally speaking, the quantification of each single item reported in Table 6 requires a detailed analysis of architectural plan disposal to achieve a detailed estimate of the number of sanitary equipment to install, the number of power sockets or electrical switches required, the amount of wall/floor tiles to lay. Unfortunately, such a detailed kind of information is not always available, especially for a large-scale loss estimation that deals with large amount of data.

To overcome this limitation, a simplified approach is proposed herein, considering that the dwelling can be subdivided into two different "ideal room" typologies, as reported in Fig. 1: generic room and bathroom. Different repair activities have been required for the considered room typologies. In fact, those related to the bathroom need additional activities respect to a generic room, basically related to the plumbing system (elementary action a.1 to a.5 of Table 6) and those related to refurbishment of wall tiles, in addition to the common activities (electrical system, radiators, refurbishment of floor tiles) required also for all the other room typologies.

Then, the quantification of each single feature reported in Table 6 for these two "ideal rooms" is firstly done. For example, for a generic room, 4 power sockets, 1 electrical switch and 1 ceiling light, 1 TV socket, 1 telephone outlet, 1 radiator, removal of floor tile, of the screed layer, supplying and re-installation of new floor tile for the corresponding surface area are considered. On the other hand, for the bathroom, the considered activities are: 2 power sockets, 2 electrical switch and 2 ceiling light installation; 1 radiator installation; the installation of water and wastewater distribution systems (including the installation of the
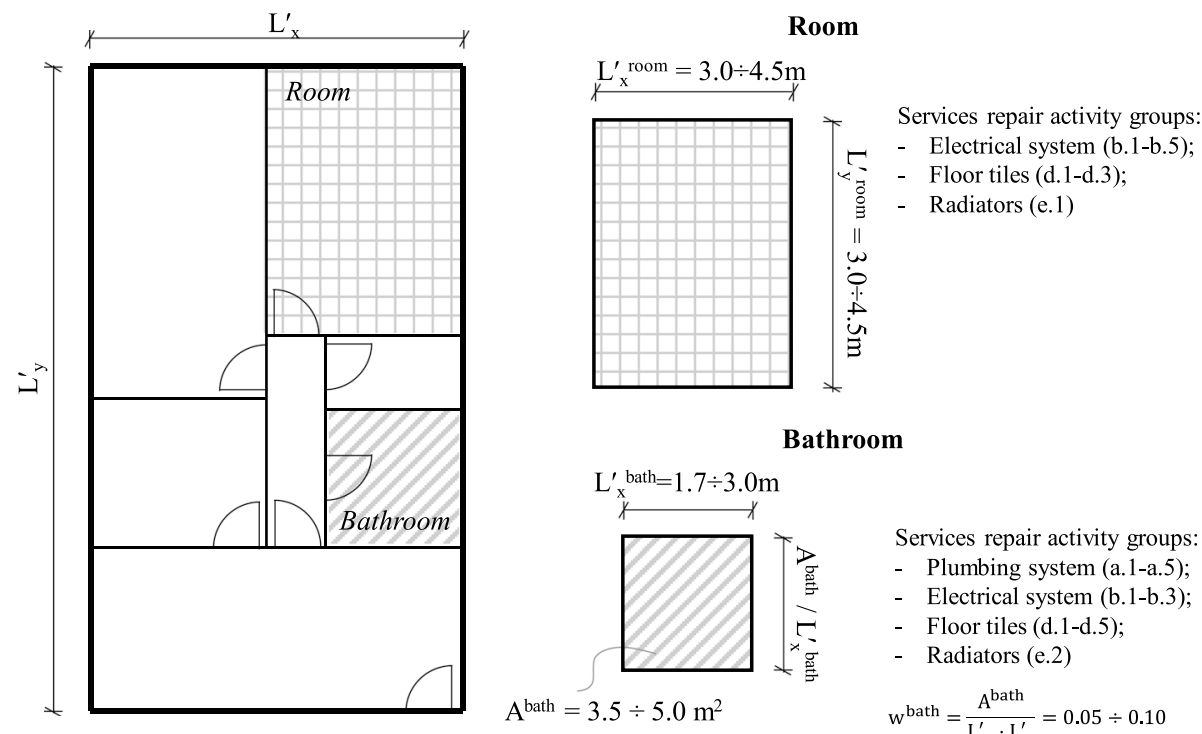

$$
\operatorname{trc}_{\mathrm{DS}_{\mathrm{i}}}^{\text {services }}=\frac{\mathrm{TRC}_{\mathrm{DS}}^{\text {room }}}{\mathrm{A}^{\text {room }}} \cdot\left(1-\mathrm{w}^{\text {bath }}\right)+\frac{\mathrm{TRC}_{\mathrm{DS}}^{\text {bath }}}{\mathrm{A}^{\text {bath }}} \cdot w^{\text {bath }}+\frac{\mathrm{TRC}_{\mathrm{DS}_{\mathrm{i}}}^{\text {general_system }}}{\mathrm{L}_{\mathrm{x}}^{\prime} \cdot \mathrm{L}_{\mathrm{y}}^{\prime}}
$$

Fig. 1 Conceptual representation of repair activities for services refurbishments and definition of weights for "ideal room" typologies 
outside waste pipes); the removal, supplying and installation of new sanitary equipment (1 Bidet, 1 Water closet, 1 Shower base, 1 Wash Basins, including faucets in all cases); removal of floor tile, of the screed layer, supplying and re-installation of new floor tile for the corresponding surface area; the removal, supplying and re-installation of wall tile for a height of $2.1 \mathrm{~m}$.

Hence, the plan dimensions for both the ideal room typologies and their weights (evaluated as the ratio of their area over the entire dwelling surface) have been defined through the introduction of the random variables (RVs) listed below:

- room plan dimensions ( $\mathrm{L}_{\mathrm{x}}^{\text {rroom }}$ and $\mathrm{L}_{\mathrm{y}}^{\text {room }}$ ), assumed as a continuous $\mathrm{RV}$ within the range [3.0; 4.5] m (Fig. 1), based on Italian Health Ministery Decree of 5 July 1975 (D.M. $75)$;

- minimum dimension of bathroom $\left(\mathrm{L}_{\mathrm{x}}^{\text {,bath }}\right)$ and its plan area $\left(\mathrm{A}^{\text {bath }}\right)$, assumed as a continuous RV within the ranges $[1.7 ; 3.0] \mathrm{m}$ and $[3.5 ; 5.0] \mathrm{m}^{2}$, respectively (Fig. 1) (D.M. 75);

- the percentage incidence (or "weight") of $\mathrm{A}^{\text {bath }}$ ( $\mathrm{w}^{\text {bath }}$ ) with respect to the plan area of the whole dwelling assumed as a continuous RV within the range [0.05; 0.10] (D.M. 75).

Lastly, repair cost for services at $\mathrm{DS}_{\mathrm{i}}, \mathrm{C}_{\mathrm{DS}_{\mathrm{i}}}^{\text {services }}$, is evaluated by averaging the repair costs related to the two "ideal rooms" on the whole dwelling surface by using their weights with respect to the total dwelling area. To this aim, $\mathrm{C}_{\mathrm{DS}_{\mathrm{i}}}^{\text {services }}$ is evaluated using a Monte Carlo simulation technique, considering a number of $\mathrm{N}=1000$ realizations, as a function of the random variables listed above, according to Eq. (4):

$$
\mathrm{C}_{\mathrm{DS}_{\mathrm{i}}}^{\text {services }}=\frac{\mathrm{C}_{\mathrm{DS}_{\mathrm{i}}}^{\text {room }}}{\mathrm{A}^{\text {room }}}\left(1-\mathrm{w}^{\text {bath }}\right)+\frac{\mathrm{C}_{\mathrm{DS}_{\mathrm{i}}}^{\text {bath }}}{\mathrm{A}^{\text {bath }}} \mathrm{w}^{\text {bath }}+\frac{\mathrm{C}_{\mathrm{DS}_{\mathrm{i}}}^{\text {general_services }}}{\left(\mathrm{L}_{\mathrm{x}} \mathrm{L}_{\mathrm{y}}{ }^{\prime}\right)}
$$

where the weight of bathroom is taken equal to $\mathrm{w}^{\text {bath }}=\mathrm{A}^{\text {bath }} /\left(\mathrm{L}_{\mathrm{x}} \mathrm{L}_{\mathrm{y}}{ }_{\mathrm{y}}\right)$, and the weight of a generic room is equal to $\left(1-\mathrm{w}^{\text {bath }}\right)$. The costs related to 1 Hot water heater, 1 Electric panel and electric backbone, $1 \mathrm{TV}$ antenna/aerial, $\mathrm{C}_{\mathrm{DS}_{\mathrm{i}}}^{\text {general_services }}$, are considered for the entire dwelling and thus divided only by the total dwelling surface area $\left(\mathrm{L}_{\mathrm{x}} \mathrm{L}_{\mathrm{y}}{ }^{\prime}\right)$.

The resulting costs for services are reported in Table 7.

Table 7 Costs for services at each DS

\begin{tabular}{llcc}
\hline $\begin{array}{l}\text { All services } \\
\text { (Activity group from “a” to “e”) }\end{array}$ & $\mathrm{C}_{\mathrm{DS} 1}^{\text {services }}\left(€ / \mathrm{m}^{2}\right)$ & $\mathrm{C}_{\mathrm{DS} 2}^{\text {services }}\left(€ / \mathrm{m}^{2}\right)$ & $\mathrm{C}_{\mathrm{DS} 3}^{\text {services }}\left(€ / \mathrm{m}^{2}\right)$ \\
\hline Mean & 0.0 & 128.8 & 258.9 \\
Median & 0.0 & 127.1 & 256.0 \\
16th prctile & 0.0 & 75.5 & 185.9 \\
84th prctile & 0.0 & 77.8 & 191.2 \\
Std & 0.0 & 28.2 & 32.8 \\
\hline
\end{tabular}




\subsection{Total repair cost evaluation}

The methodology to evaluate the TRC for infilled RC buildings follows the flowchart reported in Fig. 2. The input parameters are represented by:

- repair costs for infills and services, and

- information about damage severity, $\mathrm{DS}_{\mathrm{i}}$, and its extent, $\mathrm{DE}_{\mathrm{DSi}}$, at each $\mathrm{DS}_{\mathrm{i}}(\mathrm{i}=1,2,3)$ on infills/partitions.

Fig. 2 Flowchart of the methodology for total repair cost evaluation

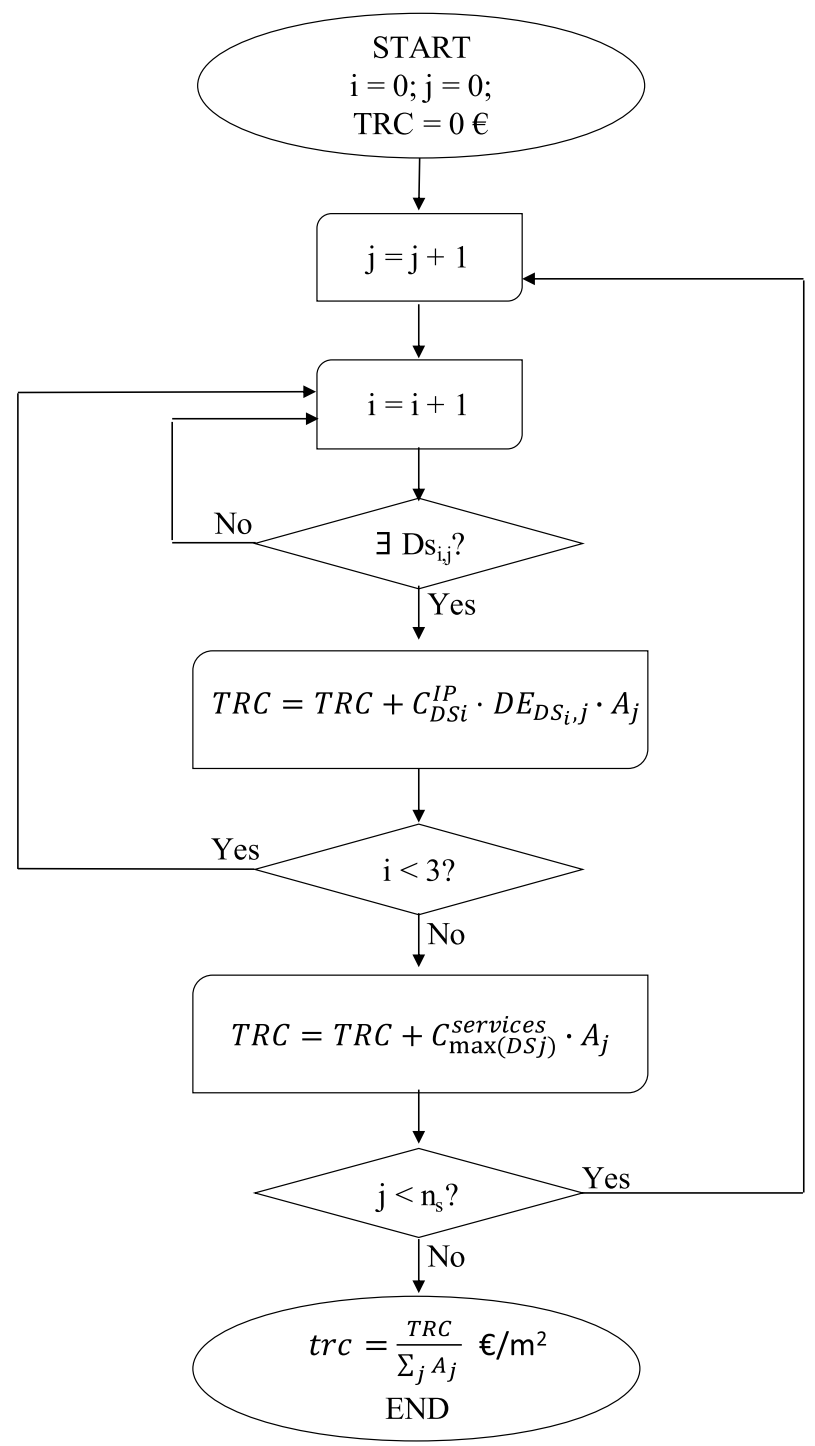


Costs for infills and services can be found in Sect. 3.1 and 3.2, respectively; information about damage severity and extent for a given building can be determined through of structural analysis or by means of data collected after post-earthquake inspections. The latter circumstance will be used in the validation phase of the procedure presented in Sects. 4 and 5.

Obviously, if no damage is observed on infills/partitions, the methodology early ends resulting in a null value for TRC. On the contrary, if at least one of the possible damage levels is observed on infills/partitions, the methodology starts with the evaluation of TRC. Moreover, different damage severity levels and extents can be attained in a building, in different parts/stories of the building. For example, a very heavy damage level for infills at the bottom stories can co-exists with a slight damage level for intermediate storeys and no damage for upper storeys. Therefore, the methodology allows summing up the repair costs of the infills/partitions characterized by $\operatorname{DS}_{\mathrm{i}}(\mathrm{i}=1,2,3)$ by simply introducing a "for-loop", by repeating the calculation three times for each storey (j-index in Fig. 2). If no infills are characterized by $\operatorname{DS}_{\mathrm{i}}(\mathrm{i}=1,2,3)$ their contribution is not considered for the TRC evaluation; otherwise the contributions of repair activities related to infills/partitions for the relevant quantities will be added to TRC.

Then, the costs due to services have to be added to costs due to infills. To this aim, the maximum DS $\left(\max \left(\mathrm{DS}_{\mathrm{j}}\right)\right)$ achieved by infills at each storey is assumed to determine the repair activities for services, as shown in Fig. 2. Note that repairing activities related to services are reasonably extended not only to the area closest to the damaged infill panels, but to the whole storey (with plan area $\mathrm{A}_{\mathrm{j}}$ ) where a given DS is attained, to guarantee a proper spatial continuity of the repairing activities (such as floor tiles replacement, for example).

In other words, the Total Repair Cost, TRC, can be evaluated as the sum, for all the storeys, of repair costs due to infills/partitions at each $\operatorname{DS}_{i}$ (for $i=1,2,3$ ), and repair costs due to services related to the maximum DS achieved storey-by-storey, as in Eq. (5a). Lastly, the specific total repair cost per plan area $(t r c)$ is evaluated as the ratio between TRC and the total plan area of the building (Eq. 5b).

$$
\begin{gathered}
\text { TRC }=\sum_{j=1}^{n_{s}} \sum_{i=0}^{3} C_{D S i}^{I P} \cdot D_{D S i, j} \cdot A_{j}+\sum_{j=1}^{n_{s}} C_{\operatorname{maxDSj}}^{\text {services }} \cdot A_{j} \\
\operatorname{trc}=\frac{T R C}{\sum_{j=1}^{n_{s}} A_{j}}
\end{gathered}
$$

It is worth noting that, for long-term prediction purposes, inflation in material prices should be considered, too, by assuming an inflation prediction model in the estimation of each necessary unit cost. However, this aspect is not investigated in the present work and does not limit the methodology and the following predicted-versus-actual costs comparisons since inflation was almost null in the reference time period for the following application (De Martino et al. 2017). 


\section{Validation by means of case-study buildings}

The procedure described in Sect. 3 is applied to evaluate the repair costs for some specific case-study buildings. These case studies are real buildings (described in more detail in Sect. 4.1), struck by L'Aquila (Italy) 2009 earthquake, for which a significant amount of detailed data has been collected during post-event reconnaissance field trips. Additionally, their damage and actual repair costs are also known in detail (Del Vecchio et al. 2018), and, thus, they can represent an important testbed for the validation of the methodology proposed herein. The comparison between predicted and actual trc is finally shown and discussed in Sect. 4.2.

\subsection{Description of case-study buildings}

The case-study buildings analyzed in this section were struck by the L'Aquila (Italy) earthquake (April 6th, 2009), a seismic event of 6.3 magnitude, resulting in IX-X grade of MCS macro-seismic scale. The main features of the event can be found in Chioccarelli et al. (2009).

Buildings selected for the purposes of this section have been previously collected and analyzed by Del Vecchio et al. (2018). They are RC moment resisting frame buildings with masonry infills for which the post-earthquake damage analysis is available. Additionally, they are well-representative of a wider database of damaged buildings related to the same seismic event (Del Vecchio et al. 2018).

More in details, buildings B1, B2 and B3, presented in Del Vecchio et al. (2018), are analyzed, since they mainly exhibited damage to infills and partitions (and very low or null damage to vertical structures, stairs and floors...). Therefore, they can represent a testbed closer to the loss assessment methodology proposed in Sect. 3, which does not account for structural components to assess seismic losses. Their main features are summarised in Table 8. Number of stories, average plan area and plan aspect ratio (PR) are obtained from the plan longitudinal and transverse dimensions reported from the explicit drawings in Del Vecchio et al. (2018).

Damage severity and extent were well-documented by photos and descriptions. In particular:

- case-study B1 presented a concentrated very heavy damage (DS3) to few infills and a more widespread (in more than $2 / 3$ of the building) slight damage (DS1);

- case-study B2 exhibited a very heavy damage (DS3) to infills and partitions in a significant portion (between $1 / 3$ and $2 / 3$ ) of the building;

- lastly, building B3 presented moderate-severe (DS2) damage and very heavy (DS3) damage to infills, and, additionally, some concentrated damage to the vertical structure (in one beam-column joint). 
Table 8 Main features of the analysed case-study buildings

\begin{tabular}{lllllll}
\hline Case-study ID & $\begin{array}{l}\text { Average } \\
\text { plan area } \\
\left(\mathrm{m}^{2}\right)\end{array}$ & PR $(-)$ & N. of stories (-) & $\begin{array}{l}\text { DE to infills/ } \\
\text { partitions }(-)\end{array}$ & $\begin{array}{l}\text { DE to vertical } \\
\text { structures }(-)\end{array}$ & $\begin{array}{l}\text { Actual trc }(€ / \\
\left.\mathrm{m}^{2}\right)\end{array}$ \\
\hline B1 & 180 & 1.65 & $4+1^{\mathrm{a}}$ & $\begin{array}{l}\text { DS3]0;1/10] } \\
\text { DS1 [2/3;1] }\end{array}$ & - & 212.1 \\
B2 & 120 & 1.67 & 3 & DS3]1/3;2/3] & - & 453.4 \\
B3 & 160 & 1.70 & $4+1^{\mathrm{a}}$ & DS3]0;1/3] & $\begin{array}{l}\text { Medium- } \\
\text { Severe]0;1/3] }\end{array}$ & 396.8 \\
\hline
\end{tabular}

a " $+1 "=a$ floor-basement-story exists

Damage severity and extent has been reported in Table 8. It should be mentioned that, in the building B1, a very small number of infill panel was interested by DS3 damage level; therefore, such a (qualitative) information has been herein converted in a numerical data assuming that less than 10\% of the exposed infill area had DS3 damage. Actual trc for these buildings according to Del Vecchio et al. (2018) are also shown in Table 8.

\subsection{Estimation of trc and comparison with the actual trc}

Data described in Sect. 4.1 have been used for the repair costs prediction, to be compared with the actual trc. Therefore, the whole procedure explained in Sect. 3 is applied. Additionally, the damage extent has been assumed as a continuous Random Variable (RV) with a uniform probability density function within the ranges of damage extent provided for each building and each DS (in Table 8). As a result, the predicted trc are shown in Table 9 and compared with the actual trc.

Mean predicted-to-actual $\operatorname{trc}$ results very close to the unity, with very slight errors for buildings B1 and B2 (-2\% and $-3 \%$, respectively). On the other hand, a higher error $(-13 \%)$ is obtained for building B3, since the latter exhibited medium-severe damage also to vertical structures. As a matter of fact, since the methodology presented herein for trc evaluation accounts for repair activities concerning infills/partitions and services, only, the predicted value slightly underestimates the actual trc.

Therefore, when a significant damage to vertical structures, or in general to other components, is observed, the methodology slightly underestimates $t r c$, neglecting their contributions. On the other hand, for those buildings where demolition and reconstruction are required, this methodology could be easily integrated considering the nominal cost of construction per cubic meter of RC structures and the total volume occupied by buildings, as, for example, reported in Cardone (2016).

Table 9 Predicted versus actual trc for the analysed case-study buildings

\begin{tabular}{llll}
\hline Case-study ID & Actual $\operatorname{trc}\left(€ / \mathrm{m}^{2}\right)$ & Predicted $\operatorname{trc}\left(€ / \mathrm{m}^{2}\right)$ & $\begin{array}{l}\text { Predicted/ } \\
\text { Actual } \operatorname{trc} \\
(-)\end{array}$ \\
\hline B1 & 212.1 & $208.1 \pm 50.4^{\mathrm{a}}$ & $0.98^{\mathrm{b}}$ \\
B2 & 453.4 & $438.1 \pm 60.7^{\mathrm{a}}$ & $0.97^{\mathrm{b}}$ \\
B3 & 396.8 & $344.9 \pm 105.6^{\mathrm{a}}$ & $0.87^{\mathrm{b}}$ \\
\hline
\end{tabular}

${ }^{\mathrm{a}}$ Mean \pm standard deviation

${ }^{\mathbf{b}}$ Ratio related to the mean predicted value 


\section{A large-scale validation by means of a "ligthtly damaged" building stock}

A further validation of the methodology described in Sect. 3 is carried out, by considering a wider dataset of infilled RC buildings. L'Aquila (Italy) 2009 earthquake is considered also in this case, since for this seismic event a significant amount of useful and extensive data has been collected during post-event reconnaissance field trips.

The building stock considered for this further step of validation was located in the epicentral area, covering about fifty municipalities. After the seismic event, it was interested by an extensive post-earthquake data collection to judge about their usability and damage level, mainly resulting damaged to infills and partitions with very slight or null damage to structural components. A preliminary analysis of these data has been already presented in De Risi et al. (2019), relating to the contribution of infills only, pointing out that predicted costs were about $50 \%$ of the actual costs. In this section, data collected for such a building stock are first briefly presented in Sect. 5.1. Repair costs are predicted, considering both infills and services, and analysed (Sect. 5.2). Lastly, predicted costs are compared with actual repair costs (Sect. 5.3) available from studies from literature (Dolce and Manfredi 2015) to show their (small) difference and stress the reliability of the loss estimation proposal for large-scale applications.

\subsection{Building stock description and damage data from post-earthquake reconnaissance field trips}

Post-earthquake reconnaissance field trips can provide useful information about suffered damage level. After L'Aquila earthquake, a significant effort was carried out for the systematic assessment by visual inspection of damaged buildings to decide about their usability rating or, eventually, the interruption of their use. Such inspections were performed by means of proper forms, the so-called "AeDES" forms (Baggio et al. 2007). Their output have been later recently published by the Italian Department of Civil Protection (DPC) on an online (Da.D.O.) platform (Dolce et al. 2019a), providing useful data about damaged buildings in the Abruzzi region. The main data obtained from this platform are synthetically reported herein, since they represent the base for the application of the methodology to this dataset.

First, the post-earthquake forms collected information about:

- building location,

- construction typology (masonry or RC),

- age of construction,

- main geometrical properties: storey number $\left(\mathrm{n}_{\mathrm{s}}\right)$, average story height $(\mathrm{h})$ and average plan area (A),

- building's use.

Additionally, information about the damage severity ("Null"; "D1—Slight", "D2-D3Medium-Severe", "D4-D5-Very heavy") and extent $(<1 / 3,1 / 3-2 / 3,>2 / 3$ of the whole building) is reported for vertical structures, floors, stairs, roof, infills and partitions or preexisting damage (as commented in Sect. 2). Damage severity is defined according to the European Macroseismic Scale (Grunthal 1998) (see Sect. 2).

Finally, the forms provide a usability rating (UR) for each building among the following: "A" (usable building), "B" (temporary unusable), "C" (partially unusable), "D" (additional investigation required), "E" (unusable building), "F" (external risk sources). 
It is worth mentioning that damage data officially released in Da.D.O. platform are herein considered without any further refinements. Their reliability is ensured by: (1) the introduction of mandatory short-courses before any survey campaign for training of inspectors on compilation of survey form (namely, the above-mentioned AeDES form), and (2) by a prompt validation procedure of each form taking advantage of the correlation between damage and usability outcomes.

The building stock investigated in this section is an extract of the whole dataset available in Da.D.O. platform. First, only residential RC infilled framed buildings have been selected. Among them, buildings with damage to infills/partitions only are considered (namely no damage exists for vertical structures, horizontal structures, stairs, roofs). In such a way, the application of the methodology described in Sect. 3, which does not account for eventual structural damage, should be able to provide predicted trc very close to the actual trc.

Such a subset of buildings can be defined as "lightly damaged" building stock, and, overall, it includes 5095 buildings. Its main features are reported in Fig. 3 in terms of:

- suffered PGA range during L'Aquila 2009 mainshock (obtained from the shake-map of the event published by National Institute of Geophysics and Volcanology according to the procedure reported in Michelini et al. 2008),

- $\quad$ average plan area (A) ranges (average value among all stories),

- number of stories $\left(\mathrm{n}_{\mathrm{s}}\right)$,

- age of construction ranges.

A significant percentage of the analysed buildings suffered a quite severe seismic shaking: $77 \%$ of buildings were subjected to a peak ground acceleration (PGA) ranging between 0.30 and $0.50 \mathrm{~g}$. About $75 \%$ of the building stock has 3 or 4 stories. A significant percentage of them (almost 73\%) was built after 1982, namely-considering their location in a very seismic prone area-they were likely designed to sustain (slight) seismic action, but according to obsolete code prescriptions.

The data collected in Da.D.O. platform allow also obtaining the damage severity and extent for each building, in agreement with the damage metric reported and commented in Sect. 2. Therefore, for the investigated dataset, it was observed that (see Table 10):

- 2406 (/5095) buildings presented no damage at all: their maximum damage level was DS0;

- 1943 (/5095) buildings presented a maximum damage level "D1- Slight", characterized by different extent ( $81.9 \%$ of them for an extent $<1 / 3$ of the whole building; $15.4 \%$ for an extent ranging between $(1 / 3$ and $2 / 3)$ of the building; the remaining $2.7 \%$ for a higher extent, i.e. $>2 / 3$ of the whole building. Therefore, such buildings are considered as characterized by a maximum damage level DS1;

- 555 (/5095) buildings presented a maximum damage "D2-D3-Medium-Severe", and, therefore, they belong to the DS2 - classified buildings. For DS2-buildings, too, different extent of damage can be observed: $52.3 \%$ of them have DS2 damage to infills in less than $1 / 3$ of the building; $33.9 \%$ and $13.9 \%$ in $(1 / 3-2 / 3)$ or $>2 / 3$, respectively, of the whole building;

- 191 buildings (i.e., $3.7 \%$ of whole building stock) have a maximum damage DS3, in the major part of the cases with an extent lower than $2 / 3$ of the whole building. 

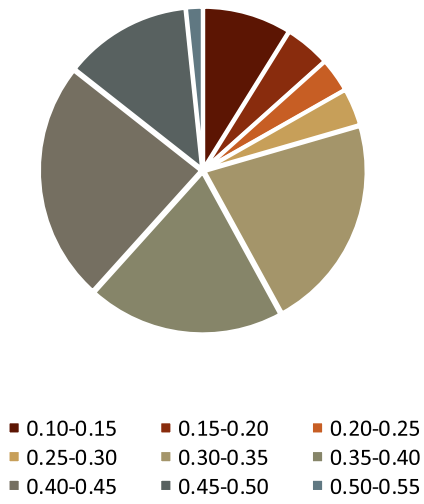

(a)

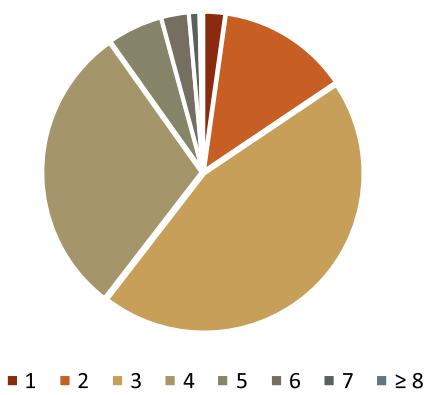

(c)

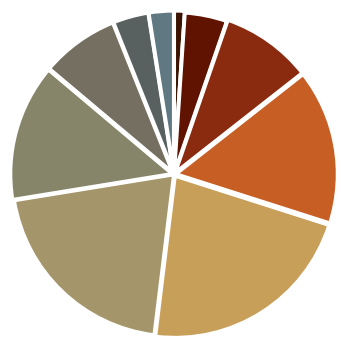

- N.A. ${ }^{*}=\leq 50=50 \div 70=70 \div 100$
$=100 \div 130=130 \div 170=170 \div 230=230 \div 300$
$=300 \div 400=\geq 400$

(b)

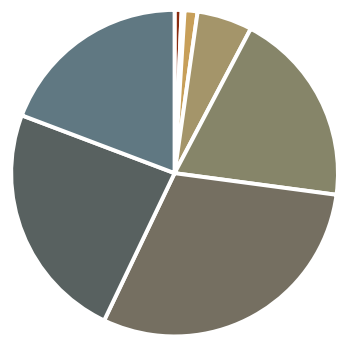

- $\leq 1919 \quad-19 \div 45 \quad-46 \div 61 \quad-62 \div 71$

- $72 \div 81 \quad-82 \div 91 \quad-92 \div 01 \quad-\geq 2002$

(d)

*N.A. $=$ Not Available

Fig. 3 Main features of the selected building stock: PGA (in g) (a), plan average area (in $\mathrm{m}^{2}$ ) (b), number of stories (c), and age of construction (d). N.A. not available

Table 10 Number and percentage of buildings belonging to the analysed dataset depending on the maximum observed DS from AeDES forms

\begin{tabular}{lllll}
\hline Maximum observed DS & DS0 & DS1 & DS2 & DS3 \\
\hline Number of buildings & 2406 & 1946 & 555 & 191 \\
Buildings percentage (\%) & 47.2 & 38.1 & 10.9 & 3.7 \\
\hline
\end{tabular}

Additionally, if $\mathrm{DS}_{\mathrm{i}}$ is the maximum damage level for a given building, a certain extent of damage $\mathrm{DS}_{\mathrm{j}}$ with $(\mathrm{j}<\mathrm{i})$ can exist. This additional information has been also collected for the investigated building stock, since necessary for a more realistic application of the loss prediction methodology. 


\subsection{Prediction of trc for a building stock}

Data and observed damage information commented in Sect. 5.1 are used herein to predict the $\operatorname{trc}$ related to the whole building stock by means of the methodology explained in Sect. 3.

Some details about the application of the methodology are necessary when managing with post-earthquake inspection forms at large-scale, as in this case, since information on damage severity and extent are not discriminated for each storey. In this case, an average measure of damage for the whole building (at each DS) is known and an "adjustment" of the flowchart in Fig. 2 is needed, both for infills and for services contributions.

Therefore, when damage severity and extent are not known storey-by-storey, Eqs. (5a) and (5b) can be simplified as shown in Eqs. (6a) and (6b):

$$
\begin{gathered}
\mathrm{TRC}=\mathrm{A} \cdot\left[\sum_{\mathrm{i}=0}^{3} \overline{\mathrm{n}}_{\mathrm{i}} \cdot\left(\mathrm{C}_{\mathrm{DSi}}^{\mathrm{IP}}+\mathrm{C}_{\mathrm{DSi}}^{\text {services }}\right)\right]=\mathrm{A} \cdot \mathrm{n}_{\mathrm{s}}\left[\sum_{\mathrm{i}=0}^{3} \mathrm{DE}_{\mathrm{DSi}} \cdot\left(\mathrm{C}_{\mathrm{DSi}}^{\mathrm{IP}}+\mathrm{C}_{\mathrm{DSi}}^{\text {services }}\right)\right] \\
\operatorname{trc}=\frac{\mathrm{TRC}}{\mathrm{n}_{\mathrm{s}} \cdot \mathrm{A}}=\left[\sum_{\mathrm{i}=0}^{3} \mathrm{DE}_{\mathrm{DSi}} \cdot\left(\mathrm{C}_{\mathrm{DSi}}^{\mathrm{IP}}+\mathrm{C}_{\mathrm{DSi}}^{\text {services }}\right)\right]
\end{gathered}
$$

where:

- A and $\mathrm{n}_{\mathrm{s}}$ are the average plan area and the number of stories, respectively, as explained before;

- $\overline{\mathrm{n}}_{\mathrm{i}}$ returns an approximation of the number of storeys affected by the ith DS and it is obtained as the product between $\mathrm{DE}_{\mathrm{DSi}}$ and the total number of storeys, $\mathrm{n}_{\mathrm{s}}$, namely $\overline{\mathrm{n}}_{\mathrm{i}}=\mathrm{DE}_{\mathrm{DSi}} \cdot \mathrm{n}_{\mathrm{s}}$;

- $\mathrm{C}_{\mathrm{DSi}}^{\mathrm{IP}}$ and $\mathrm{C}_{\mathrm{DSi}}^{\text {services }}$ are repair costs per floor unit for infills/partitions and services reported in Tables 5 and 7, respectively.

Obviously, the product $\left(\mathrm{DE}_{\mathrm{DSi}} \cdot \mathrm{n}_{\mathrm{s}}\right)$ is a real number and have to be approximated to an integer number. Therefore, hereinafter two extreme bounds have been considered to provide a range of values for TRC (minimum and maximum values), as shown in Eq. (7):

$$
\overline{\mathrm{n}}_{\mathrm{i}}^{\min }=\operatorname{floor}\left(\mathrm{DE}_{\mathrm{DSi}} \cdot \mathrm{n}_{\mathrm{s}}\right) \quad \overline{\mathrm{n}}_{\mathrm{i}}^{\max }=\operatorname{ceil}\left(\mathrm{DE}_{\mathrm{DSi}} \cdot \mathrm{n}_{\mathrm{s}}\right)
$$

where the floor and ceil functions return the nearest integer less than or equal to and the nearest integer greater than or equal to the input real number, respectively. The resulting evaluation of $t r c$ will be defined below as $\operatorname{trc}_{\min }$ and $\operatorname{trc}_{\max }$ (lower and the upper bounds, respectively). In both cases, it must be verified that:

$$
\left\{\begin{array}{l}
\bar{n}_{3} \leq \mathrm{n}_{\mathrm{s}} \\
\bar{n}_{i} \leq \mathrm{n}_{\mathrm{s}}-\sum_{\mathrm{k}=\mathrm{i}+1}^{3} \overline{\mathrm{n}}_{\mathrm{k}} \quad \text { with } i=1,2
\end{array}\right.
$$

to guarantee that: (1) damaged (plan) area always results lower or equal to $\left(n_{\mathrm{s}} \cdot \mathrm{A}\right)$ due to aforementioned approximations, and (2) if, in a given storey, the contemporaneity of two or 
more DSs occurs, the repair activities to be performed are those related to the most severe one only (otherwise the same repairing activities would be wrongly computed more times).

Furthermore, when managing with post-earthquake inspection forms, some information are generally not deterministically known but available within given ranges, i.e., plan area (A) and damage extent $\mathrm{DE}_{\mathrm{DSi}}$. Therefore, a Montecarlo simulation is applied to generate 1000 samples different for:

- plan area, A, assumed as uniformly distributed RV within the range provided by the AeDES form for each building (see Fig. 3b);

- and damage extent, $\mathrm{DE}_{\mathrm{DSi}}$, assumed as uniformly distributed $\mathrm{RV}$ within the ranges: ]0; $1 / 3$ ], ]1/3; 2/3], ]2/3; 1], for each building.

Finally, to fully compute seismic losses by means of Eq. (6), for each of the 1000 samples obtained from the Montecarlo simulation, a value of $\mathrm{C}_{\mathrm{DSi}}^{\mathrm{IP}}$ and a value of $\mathrm{C}_{\mathrm{DSi}}^{\text {services }}$ are extracted from a lognormal distributions obtained from parameters reported in Tables 5 and 7.

It is worth noting that, based on these assumptions, two different "average damage" $(\overline{\mathrm{DS}})$ distributions along the building's height can be associated to each building, related to the minimum or the maximum damage conditions for that building, assuming that $\overline{\mathrm{DS}}$ can be expressed as in Eq. (9):

$$
\overline{\mathrm{DS}}=\sum_{i=0}^{3}\left(\mathrm{DE}_{\mathrm{DSi}} \cdot \mathrm{i}\right)=\frac{1}{\mathrm{n}_{\mathrm{s}}} \sum_{\mathrm{i}=0}^{3}\left(\overline{\mathrm{n}}_{\mathrm{i}} \cdot \mathrm{i}\right)
$$

In Eq. (9), $\bar{n}_{i}$ is equal to $\bar{n}_{i}^{\min }$ or $\bar{n}_{i}^{\max }$ for the minimum or the maximum damage condition, respectively.

Figure 4 shows 50th, 16th and 84th percentiles (prctile) of such $\overline{\mathrm{DS}}$ distribution, obtained for each group of buildings belonging to the dataset characterized by the

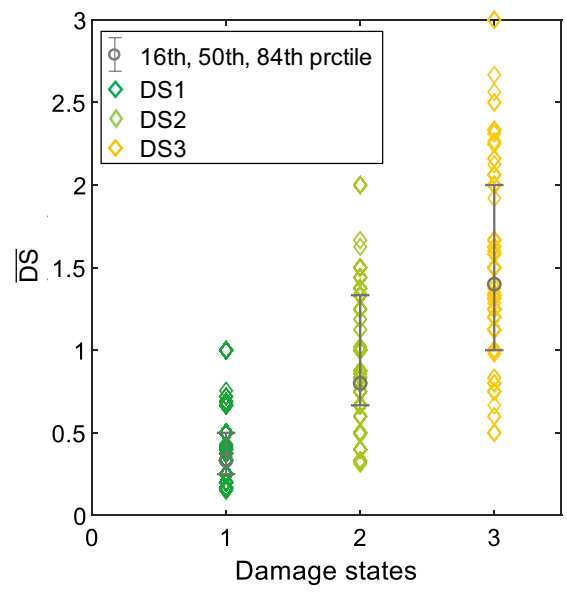

(a)

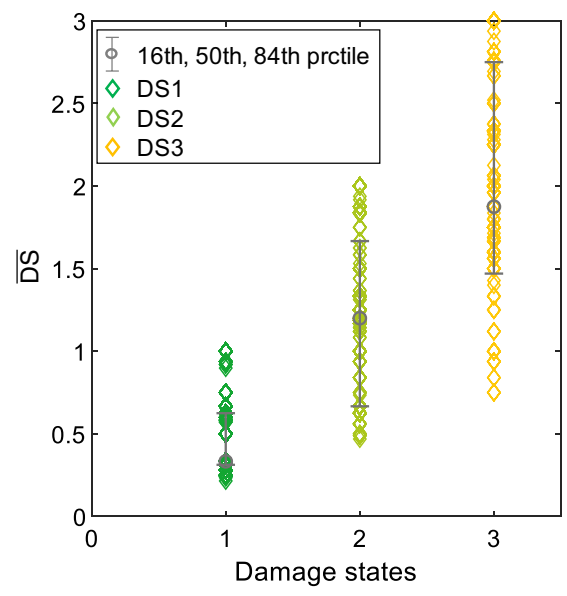

(b)

Fig. 4 Average damage level distribution depending on the maximum achieved DS: lower (a) and upper (b) bound 
DS1
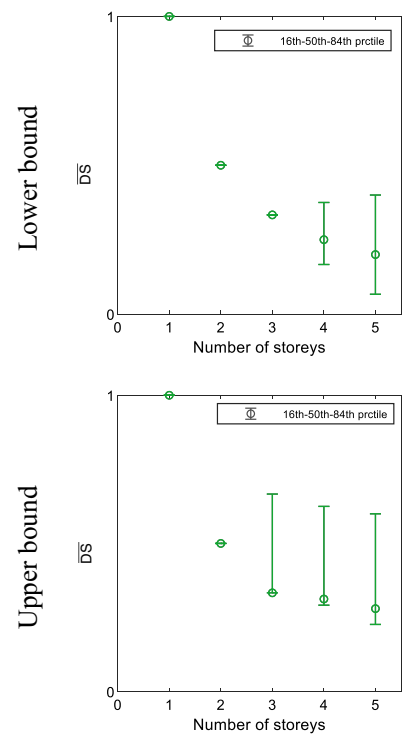

DS2
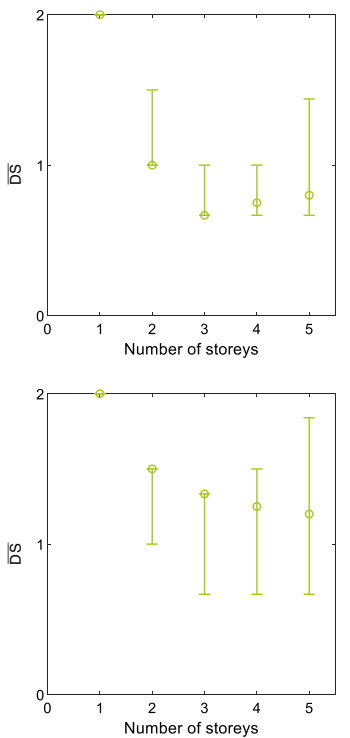

DS3
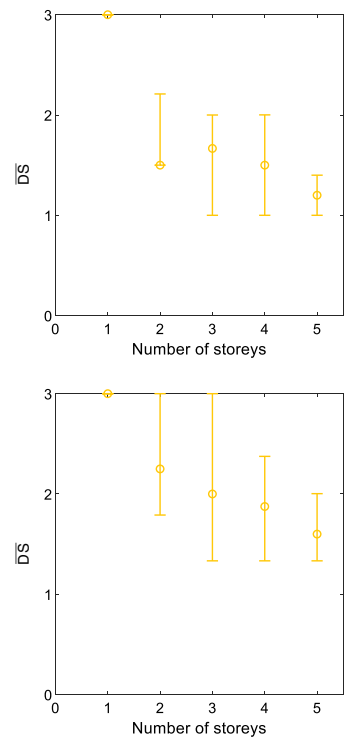

Fig. 5 16th, 50th and 84th of average damage level distribution depending on the number of stories

achievement of the same maximum DS. The minimum and maximum damage conditions are represented in Fig. 4a and Fig. 4b, respectively. It can be noted that, for each building, $\overline{\mathrm{DS}}$ is always lower than the corresponding maximum DS achieved in that building.

The average damage level $\overline{\mathrm{DS}}$ can be also related to the number of stories, $\mathrm{n}_{\mathrm{s}}$, of each building belonging to the dataset, as shown in Fig. 5, where buildings are grouped

Fig. 6 Statistics of predicted trc for the investigated building stock depending on the maximum DS: upper and lower bounds for $\operatorname{trc}$

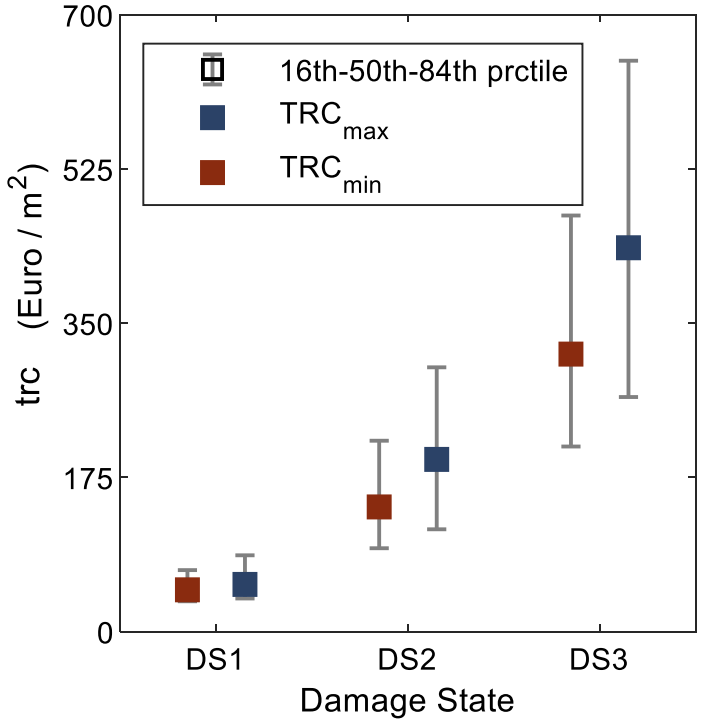


depending on the maximum achieved DS (from DS1 to DS3). Note that $\mathrm{n}_{\mathrm{s}}$ has been limited to 5 , since buildings with a number of stories bigger than 5 are very rare (see Fig. 3c). Both the lower and the upper damage conditions have been reported. In both cases, at DS1 and DS2, the $\overline{\mathrm{DS}}$ tends to decrease when $\mathrm{n}_{\mathrm{s}}$ increases from 1 to 3 stories, then keeping a pseudo-constant value (on average) for taller buildings. At DS3, a decreasing trend of $\overline{\mathrm{DS}}$ is observed from 1 to 5 stories. Such a decreasing trend can be likely ascribable to a concentration of damage at the lower stories for taller buildings.

\subsubsection{Predicted trc}

The results of the procedure explained above are reported in Fig. 6, depending on the maximum DS observed after the seismic event. Figure 6 shows 50th (median), 16th, and 84th percentiles (prctile) of the estimated trc both in the lower and in the upper bound hypotheses.

It can be noted that, median $\operatorname{trc}$ value varies from 47.5 to $53.6 € / \mathrm{m}^{2}$ when the maximum observed DS is DS1; it ranges between 141.5 and $195.5 € / \mathrm{m}^{2}$ at DS2; 315.0 to $435.6 € / \mathrm{m}^{2}$ are required at DS3, as median $\operatorname{trc}$ value. Note that $\operatorname{trc}$ values shown in Fig. 6 are characterized by a high variability, since they are provided as a function of the maximum observed DS (maxDS) only.

Nevertheless, a lower variability in trc prediction can be obtained if co-existing damage and its extent are also considered, namely if $t r c$ is expressed as a function of the average damage level ( $\overline{\mathrm{DS}}$ ) defined above (see Eq. 9). In Fig. 7, $\operatorname{trc}$ is shown as a function of $\overline{\mathrm{DS}}$ for both the lower and the upper trc bounds. Separated plots are presented depending on the

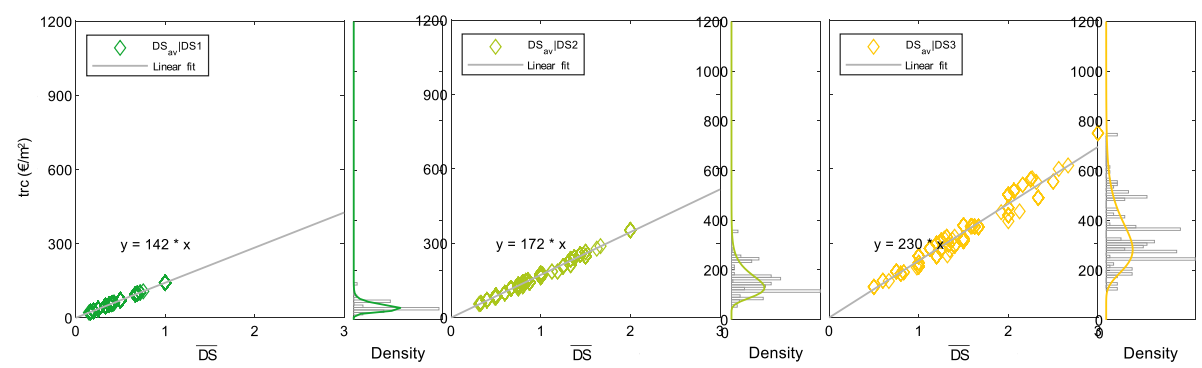

(a)

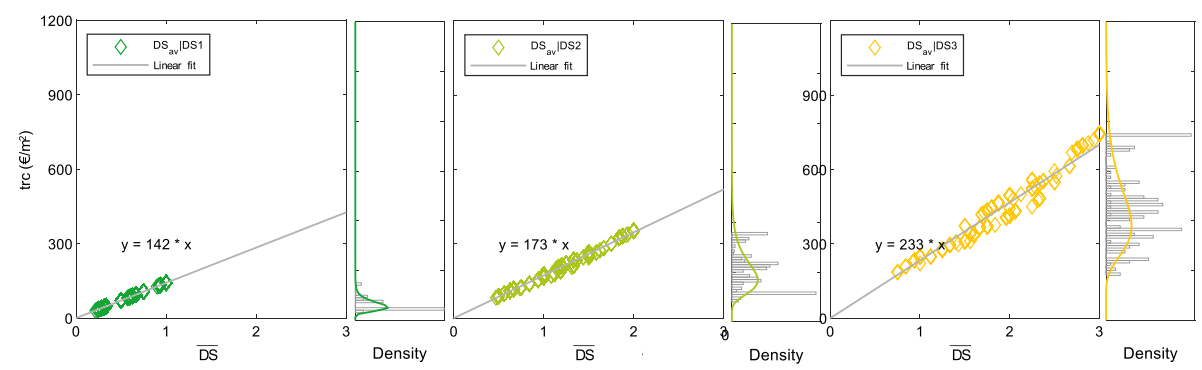

(b)

Fig. 7 Lower (a) and upper (b) bounds of trc depending on average damage level $\left(\overline{\mathrm{DS}}=\mathrm{DS}_{\mathrm{av}}\right)$ 

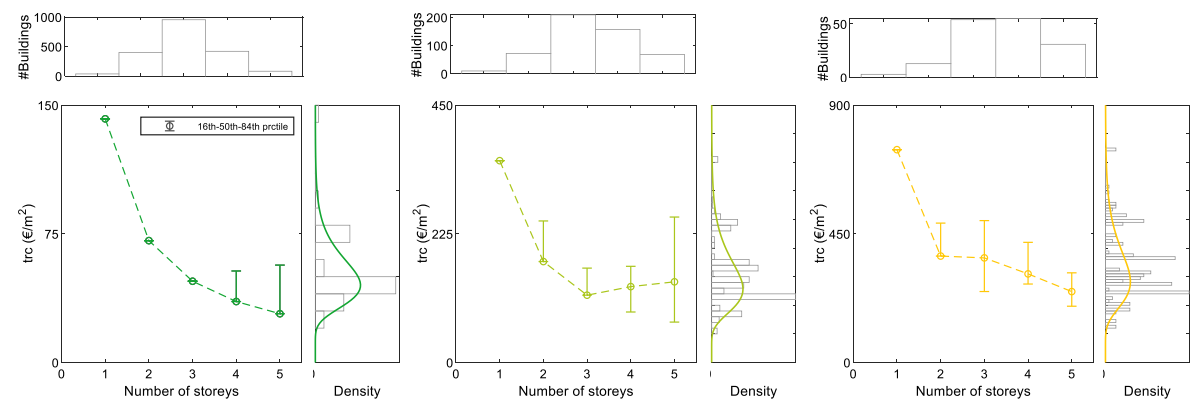

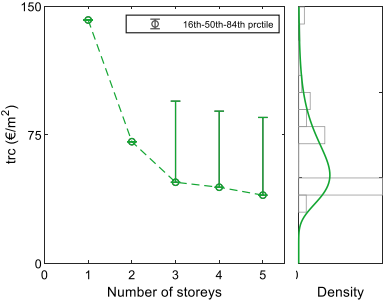

(a)
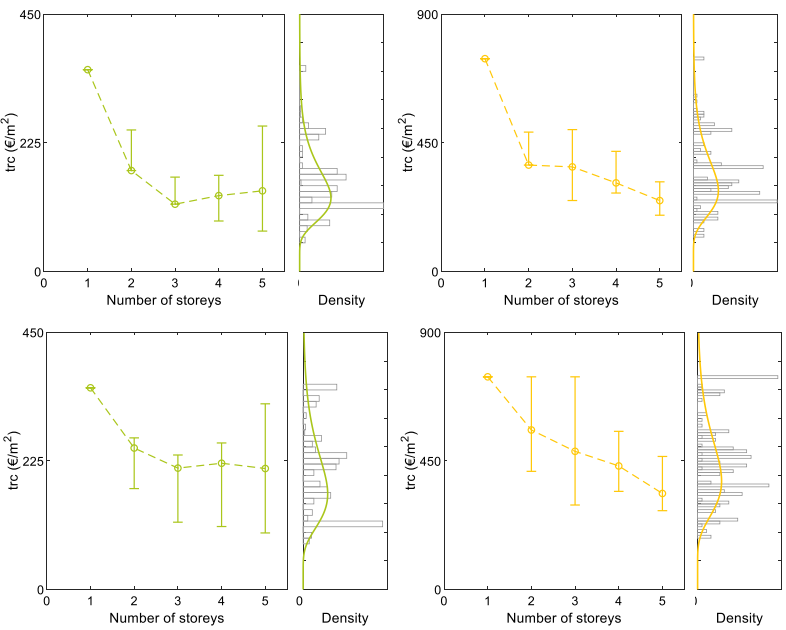

(c)

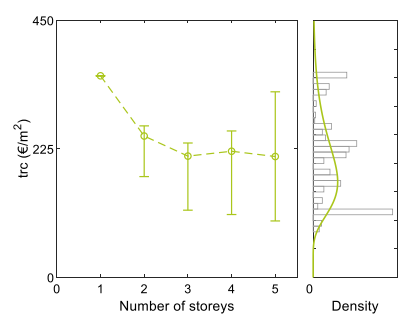

(b)

Fig. 8 trc depending on the number of storeys when the maximum achieved DS is DS1 (a), DS2 (b), or DS3 (c) - lower (first row) and upper (second raw) bounds. On the top: frequency distribution of buildings' $\mathrm{n}_{\mathrm{s}}$

maximum DS achieved by each of the analyzed buildings, together with the frequency distributions of $t r c$ interpolated with a log-normal probability density function. First, it can be observed that a clear linear trend exists between the average damage and the estimated trc, with an increasing slope for increasing maximum damage severity, as expected. Additionally, $\operatorname{trc}$ points are very close to such a linear fitting, thus highlighting that $t r c$ can be better predicted-or better "explained"-by $\overline{\mathrm{DS}}$ than by the maximum achieved DS. In other words, if the average damage is known, the trc value can be computed with a lower dispersion with respect to prediction based on the maximum achieved DS only. Obviously, when the average damage is exactly equal to a given maximum $\operatorname{DS}_{\mathrm{i}}$ (with $\mathrm{i}=1,2,3$ ), $\operatorname{trc}$ can be very easily computed as the sum of the repair costs per floor unit related to infills and services (coming from Tables 5 and 7, respectively) at that $\mathrm{DS}_{\mathrm{i}}$. In these specific cases, it can be easily verified that the ratio between $\operatorname{trc}$ and $\overline{\mathrm{DS}}\left(=\mathrm{DS}_{\mathrm{i}}\right)$ is very close to the slope of the linear fittings plotted in Fig. 7.

Given the trend of $t r c$ with the average damage $\overline{\mathrm{DS}}$ (Fig. 7) and the trend of $\overline{\mathrm{DS}}$ with the number of stories $n_{s}$ (Fig. 5), it can be useful to show how $\operatorname{trc}$ varies with $n_{\mathrm{s}}$, as in Fig. 8. Note that the number of stories and the maximum achieved DS are information easier to know with respect to the average damage (which also requires the knowledge of the damage extent). Therefore, the prediction of $\operatorname{trc}$ depending on $\mathrm{n}_{\mathrm{s}}$ and maximum achieved DS can be certainly easier to perform. Figure 8 shows that such trend reflects what was already shown and explained in Fig. 5, as expected, due to the almost linear relationship between $\operatorname{trc}$ and $\overline{\mathrm{DS}}$. Therefore, $\operatorname{trc}$ decreases, on average, when $\mathrm{n}_{\mathrm{s}}$ varies from 1 to 3 when the maximum achieved damage is DS1 or DS2, then keeping an almost constant value for higher $\mathrm{n}_{\mathrm{s}}$. At DS3, a decreasing trend of $t r c$ is observed, on average, for $n_{s}$ varying from 1 to 5 . The clear trend of the $\operatorname{trc}$ with the number of stories allows to (partially) explain the variability of the trc shown in Fig. 6. 
Figure 8 also shows that $\operatorname{trc}$ values for 1-storey buildings are always equal to the sum of unit costs for infills/partitions and services reported in Tables 5 and 7 $\left(\mathrm{C}_{\mathrm{DSi}}^{\mathrm{IP}}+\mathrm{C}_{\mathrm{DSi}}^{\text {services }}=\mathrm{C}_{\mathrm{DSi}}\right)$ at the ith DS. This is the consequence of an implicit assumption, i.e., whenever a building resulted damaged according to inspection data, regardless from severity and extension, at least one story must be affected by repairing activities in both the lower and the upper damage bounds, otherwise a zero value of trc would be related to a non-zero value of $\overline{\mathrm{DS}}$. On the contrary, for taller buildings, a certain degree of damage distribution along the building's height can be observed. Therefore, the repair cost results lower than the totality of the sum between $\mathrm{C}_{\mathrm{DSi}}^{\mathrm{IP}}$ and $\mathrm{C}_{\mathrm{DSi}}^{\text {services }}$. Based on this concept, data reported in Fig. 8 could be equivalently expressed in "dimensionless" form, as shown in Eq. (10):

$$
\begin{aligned}
\operatorname{trc}=\sum_{\mathrm{i}=0}^{3} \mathrm{DE}_{\mathrm{DSi}} \cdot\left(\mathrm{C}_{\mathrm{DSi}}^{\mathrm{IP}}+\mathrm{C}_{\mathrm{DSi}}^{\text {services }}\right)=\sum_{\mathrm{i}=0}^{3} \mathrm{DE}_{\mathrm{DSi}} \cdot\left(\mathrm{C}_{\mathrm{DSi}}\right) \\
\frac{\operatorname{trc}}{\mathrm{C}_{\mathrm{DS} 1}^{50}}=\frac{1}{\mathrm{C}_{\mathrm{DS} 1}^{50}} \sum_{\mathrm{i}=0}^{1} \mathrm{DE}_{\mathrm{DSi}} \cdot \mathrm{C}_{\mathrm{DSi}} \\
\frac{\operatorname{trc}}{\mathrm{C}_{\mathrm{DS} 2}^{50}}=\frac{1}{\mathrm{C}_{\mathrm{DS} 21}^{50}} \sum_{\mathrm{i}=0}^{2} \mathrm{DE}_{\mathrm{DSi}} \cdot \mathrm{C}_{\mathrm{DSi}} \\
\frac{\operatorname{trc}}{\mathrm{C}_{\mathrm{DS} 3}^{50}}=\frac{1}{\mathrm{C}_{\mathrm{DS} 3}^{50}} \sum_{\mathrm{i}=0}^{3} \mathrm{DE}_{\mathrm{DSi}} \cdot \mathrm{C}_{\mathrm{DSi}}
\end{aligned}
$$
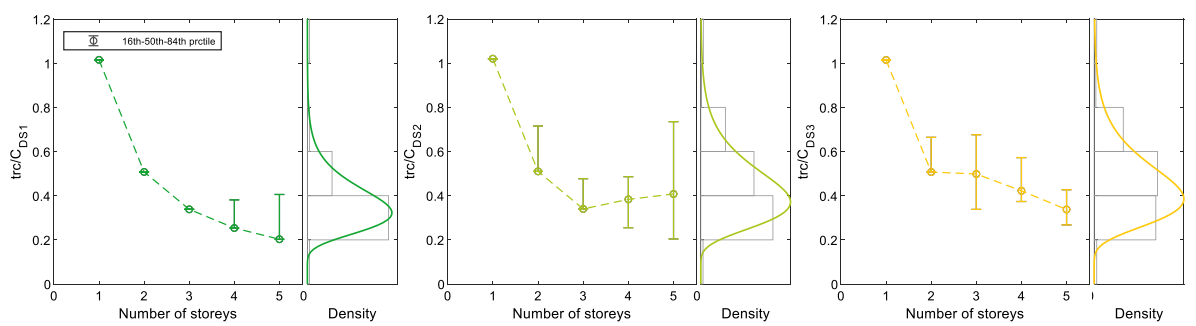

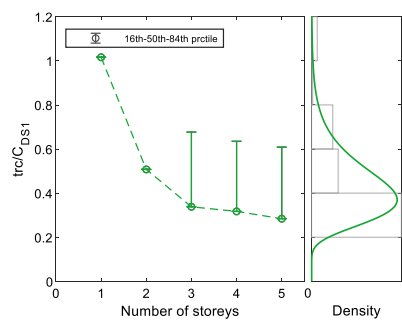

(a)

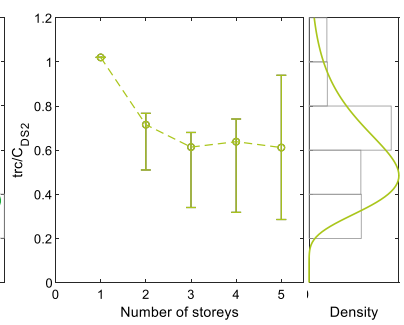

(b)

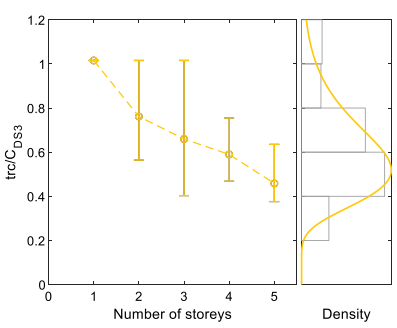

(c)

Fig. 9 trc-to- $\mathrm{C}_{\mathrm{DSi}}^{50}$ ratio depending on the number of storeys when the maximum achieved DS is DS1 (a), DS2 (b), or DS3 (c)-lower (first row) and upper (second raw) bounds 
DS1
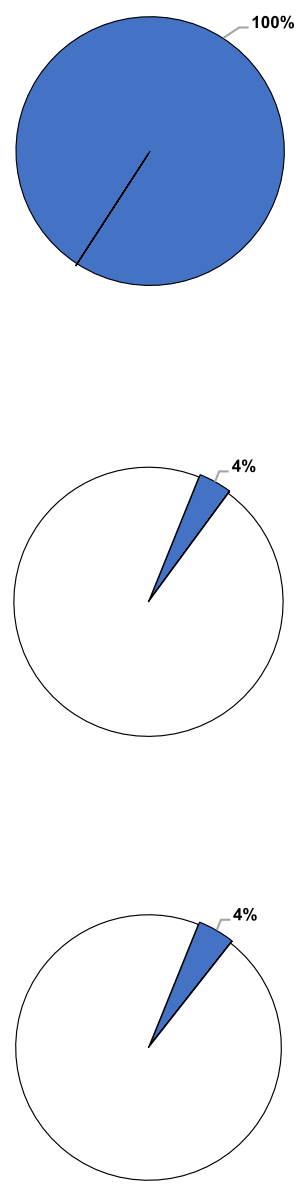

DS2

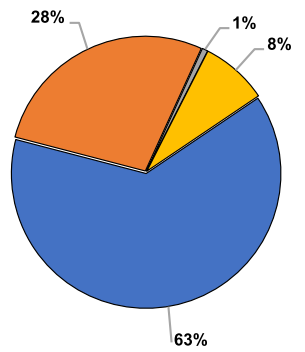

(a)

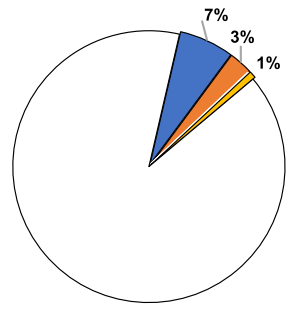

(b)
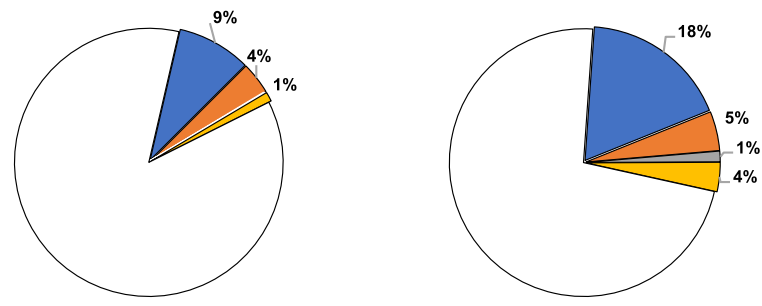

(c)

- IP "PS " ES " FWT

Fig. 10 De-aggregation of the predicted of trc depending on the component (IP=infills/partitions; PS plumbing system, $E S$ electrical system, $F W T$ floor/wall tiles): average percentage incidence of each component with respect to the sum of the components (valid for both the lower and the upper bound of the predicted $t r c)$ (a); average percentage incidence of each component with respect to the reconstruction cost of the whole building, for the lower (b) and the upper (c) bound of the predicted trc

where $\mathrm{C}_{\mathrm{DSi}}^{50}$ (with $1=1,2,3$ ) are the median values of $\mathrm{C}_{\mathrm{DSi}}$. By applying Eq. (10) to predicted trc values, data shown in Fig. 8 can be "converted" in data reported in Fig. 9. In other words, if the maximum DS achieved by a given building and its number of stories are known, predicted trc can be assumed as a fraction, lower or equal than the unity, of $\mathrm{C}_{\mathrm{DSi}}$, as shown in Fig. 9. The ratios trc/ $\mathrm{C}_{\mathrm{DSi}}$ in Fig. 9 can be, thus, regarded as coefficients of damage distribution of each maximum $\mathrm{DS}_{\mathrm{i}}$ depending on the number of storeys. 


\subsubsection{Component-by-component de-aggregation}

Additionally, for each maximum DS, the percentage incidence of all the considered cost items can be evaluated, as reported in Fig. 10. More in details, the component "IP" includes all the costs related to repairing activities for infill panels; the item "PS = Plumbing System" includes costs for activities (h) and (i) of Table 6; the component "ES = Electrical System" includes costs for activities (j) of Table 6; "FWT $=$ Floor/Wall Tiles" is related to activities groups (k) and (1), as specified in Sect. 3. All these cost items already include technical costs (as shown in Tables 2 and 6).

In Fig. 10a the same percentage incidences of each cost item ("IP", PS", "ES", "FWT") are observed in both the upper and the lower bound of $t r c$, since the cost items are obtained by multiplying their unit costs by the same coefficients (i.e., $\bar{n}_{i}^{\min }$ or $\bar{n}_{i}^{\max }$ shown in Eq. (7) for the lower and upper bound, respectively), thus keeping invariant their proportion with respect to $t r c$.

When the maximum damage is DS1, the whole trc is due to the repairing activities related to infills/partitions (Component "IP"). Repair costs related to plumbing ("PS"), electrical system ("ES") and floor/wall tiles ("FWT") are null at DS1 because repairing activities related to services are assumed to be not necessary for a very low damage level at infills (Sect. 3).

When the maximum damage level is DS2, repair costs related to infills/partitions and plumbing system are comparable, on average. Only $8 \%$ of the estimated trc is due to floor/ wall tiles replacement. Technically null (1\%) is the percentage incidence of repairing activities related to the electrical system.

Lastly, for buildings with maximum damage level DS3, on average, $65 \%$ of the estimated $t r c$ is due to infills and partitions. Note that the incidence of infills/partitions at DS3 also includes costs due to replacement of openings (windows/doors), which represents a not negligible portion of the total repair activities related to infills (about 25\%), as found in Del Gaudio et al. (2019b). At DS3, only 5\% to the electrical system, and the remaining portion is divided between plumbing system (17\%) and floor/wall tiles (13\%).

In summary, on average, repair cost due to infills and partitions represents about sixty percent of the whole $\operatorname{trc}$ at DS2-DS3, namely for medium level of damage, as also found in Del Vecchio et al. (2019).

The average percentage incidence of each component with respect to the total reconstruction cost of the whole building can be also computed as shown in Fig. 10b,c, by assuming that the latter is equal to $1192 € / \mathrm{m}^{2}$, as suggested by Di Ludovico et al. (2017a) based on actual data related to L'Aquila (Italy) city.

It can be noted that at DS2 the repair costs due to "IP", "PS", "ES", and "FWT" range from 11 to $14 \%$ of the reconstruction cost, namely it is in very good agreement with data analysis reported in Di Pasquale et al. (2005) and Cosenza et al. (2018). In particular, the latter study indicated that repair cost is equal to $15 \%$ of the reconstruction cost at Damage Limitation Limit State-as defined in Italian (D.M. 2008, 2018) or European (CEN 2004) codes - namely at a "limit state" that can be assumed as coincident with the damage state DS2 investigated in this work (Sassun et al. 2016; Del Gaudio et al. 2019b).

Lastly, the sum of repairing activities required for "IP", "PS", "ES", and "FWT" fall within the ranges $[4 ; 4.5] \%$ and $[20 ; 28] \%$ of the total reconstruction cost, at the DS1 and DS3, respectively, considering the lower and upper bounds of trc. 


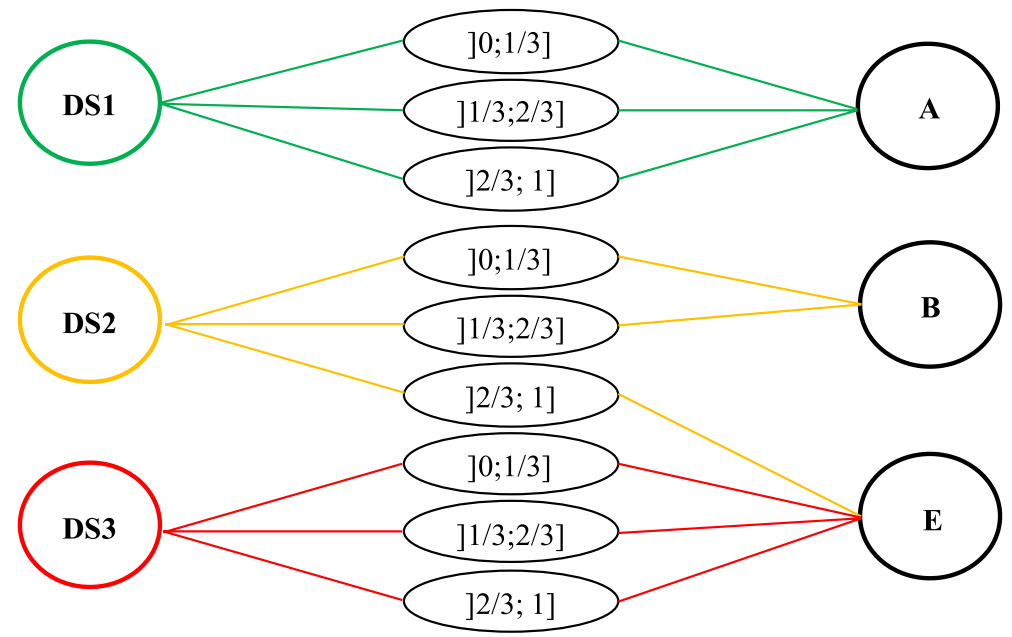

Fig. 11 Conversion from maximum DS and its damage extent to usability rating

Fig. 12 Statistics of predicted trc for the investigated building stock depending on the usability rating

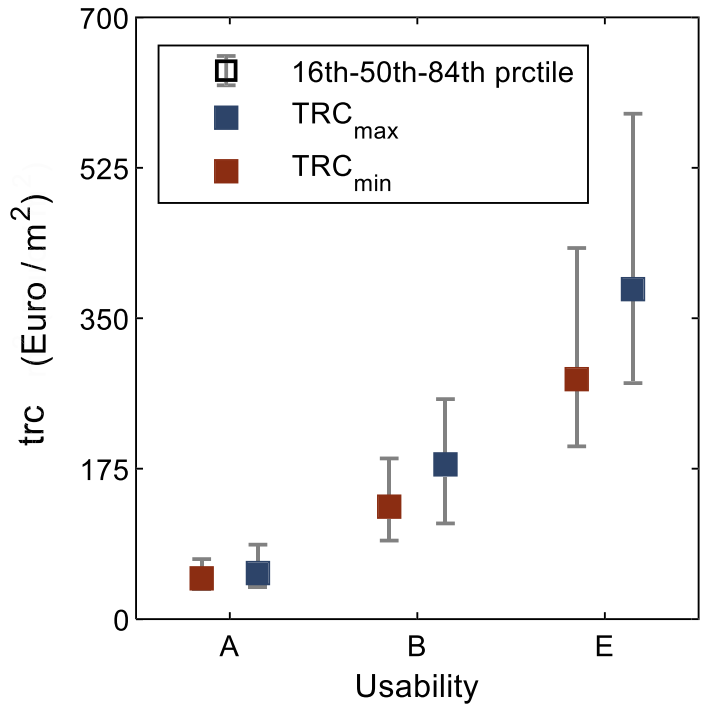

\subsection{Comparison between predicted trc and actual trc}

Predicted trc are finally compared herein with the actual repair costs. First note that predicted repair costs have been obtained until now depending on the maximum DS or on the average damage. On the contrary, the actual $t r c$ have been provided in the literature (Dolce and Manfredi 2015; Di Ludovico et al. 2017a, b) thanks to an extensive and detailed analysis of the actual design documents realised during L'Aquila reconstruction process, depending on the Usability Rating (UR) of the buildings. Possible URs, ordered from "A" to "F", have been introduced in Sect. 5.1 (more detailed description can be found in Baggio et al. 
2007), and they synthetically represented the main parameter to define the reconstruction refund level. Additionally, only URs "A", "B" and "E" are considered herein (as in previous literature, e.g., Dolce and Manfredi 2015; Di Ludovico et al. 2017a, b) since a definitive and rational interpretation of URs "C", "D", or "F" is not trivial when a large subset of data is managed. Therefore, a conversion from observed DS (with its extent) to UR is necessary in order to compare predicted and actual repair cost.

The conversion assumed herein is reported in Fig. 11, based on (1) the DSs description reported in Sect. 2 and (2) Baggio et al. (2007)'s suggestions (which represents the main basis of the AeDES form). As shown in Fig. 11, DS1 corresponds to UR "A" (i.e., usable building); DS2 corresponds to UR "B" (i.e., temporary unusable) if its extent is lower than $2 / 3$ of the whole building; otherwise the resulting UR is "E" (i.e., unusable building). Obviously, UR "A" includes also undamaged buildings (with maximum damage DS0).

Given the assumptions in Fig. 11, predicted trc can be finally obtained depending on the UR. Figure 12 shows 50th (median), 16th, and 84th percentiles (prctile) of the estimated $\operatorname{trc}$ depending on the UR, both in the lower $\left(\operatorname{trc}_{\min }\right)$ and in the upper $\left(\operatorname{trc}_{\max }\right)$ bound hypotheses introduced in the previous section. Note that when the repair costs for "A" buildings must be evaluated, only buildings in DS1 are considered, since buildings in DS0 should be undamaged and thus repairing activities should be not necessary.

As mentioned before, actual trc can be obtained in the literature from Dolce and Manfredi (2015).

First, Dolce and Manfredi (2015) provides the mean repair cost for buildings characterised by UR "B". Then, actual trc for UR "E" are divided in two categories (according to Dolce and Manfredi 2015): the first one is related to UR "E" mainly due to severe damage to the vertical structures, roofs,...; the second one is a special class of buildings, classified as "E-B", which were characterised by UR "E" mainly due to the damage to infills and partitions. This means that only actual trc for buildings with "E-B" should be compared with the predicted $t r c$, since the building stock investigated in this section presents no damage to structural components different from infills and partitions.

Dolce and Manfredi (2015) also provide standard deviation values for actual costs $\left(\operatorname{std}_{\text {trc }}\right)$ related to buildings with UR "B" and "E-B". Unfortunately, such values of actual $\operatorname{std}_{\text {trc }}$ includes the variability of both repair costs and retrofitting costs. Therefore, actual $\mathrm{std}_{\text {trc }}$ is expected to be higher than standard deviation of actual costs related to repairing activities only, like those predicted in this work.

Actual trc for UR "A" were not known from actual repairing activities required for very slightly damaged buildings. Nevertheless, for buildings resulting in UR " $A$ " that exhibited a very slight damage after L'Aquila 2009 earthquake, Italian government funded the necessary repairing activities with a flat-rate amount of money, at maximum equal to $10,000 €$ per dwelling (Dolce and Manfredi 2015; OPCM 3778 6/06/2009). Therefore, if the number

Table 11 Predicted versus actual mean values of trc

\begin{tabular}{lllll}
\hline UR & $\begin{array}{l}\text { Mean predicted trc } \\
\left(€ / \mathrm{m}^{2}\right)\end{array}$ & $\begin{array}{l}\text { Mean predicted } \mathrm{trc}_{\max } \\
\left(€ / \mathrm{m}^{2}\right)\end{array}$ & $\begin{array}{l}\text { Mean actual trc } \\
\left(€ / \mathrm{m}^{2}\right)\end{array}$ & $\begin{array}{l}\text { Mean predicted } \\
\text { trc/mean actual } \\
\text { trc }(-)\end{array}$ \\
\hline $\mathrm{A}$ & 52.3 & 62.0 & 64.0 & $0.82-0.97$ \\
$\mathrm{~B}$ & 140.5 & 186.3 & 183.8 & $0.76-1.01$ \\
$\mathrm{E}-\mathrm{B}^{\mathrm{a}}$ & 311.3 & 421.6 & 342.4 & $0.91-1.23$ \\
\hline
\end{tabular}

aClassified as "E-B" in Dolce and Manfredi (2015) 
Fig. 13 Predicted versus actual trc

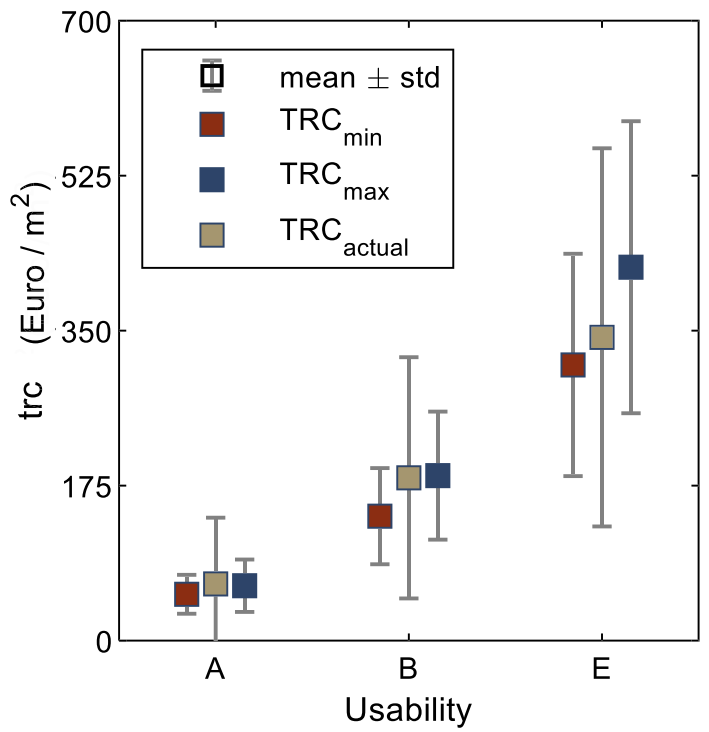

of stories, the average plan area and the number of dwellings per each building resulting in UR "A" (maximum damage DS1) are obtained from Da.D.O. platform data, the actual repair cost (with its std $_{\text {trc }}$ ) can be obtained also for UR “A"-buildings.

In summary, mean values of actual trc obtained according to Dolce and Manfredi (2015) for UR "A", "B" and "E-B" are reported in Table 11 and compared with predicted mean trc values. It can be noted that predicted and actual mean values of trc are quite close to each other. For buildings with UR "A" and "B", actual costs are slight underestimated (- $11 \%$, on average between $t r c_{\min }$ and $t r c_{\max }$ ). When buildings with UR "E-B" are considered, on average, the percentage relative prediction error is significantly low (equal to $+7 \%$ ).

Finally, Fig. 13 shows the comparison between actual and predicted costs in terms of mean $\operatorname{trc} \pm \mathrm{std}_{\mathrm{trc}}$. It can be noted that $\mathrm{std}_{\text {trc }}$ values related to both the lower and the upper bounds of $t r c$ describe a wider range of variability of the predicted $t r c$, ascribable to the uncertainty in the knowledge of the storey-by-storey extent of repairing activities (as explained in Sect. 5.2). Despite such aspect, the actual variability is higher than the predicted one (also combining together $\operatorname{trc}_{\min }$ and $\operatorname{trc}_{\max }$ hypothesis), likely mainly due to the inclusion of the variability related to retrofitting costs, too, in the actual $\mathrm{std}_{\text {trc }}$ values provided by Dolce and Manfredi (2015).

\section{Conclusions and further developments}

In this work, a component-based methodology to predict seismic losses for residential RC structures has been proposed, focusing on the contribution of masonry infills/partitions and services. It can be used starting from the expected damage level to infills and partitions, both (1) predicted by means of numerical tools or (2) directly obtained by post-earthquake in situ surveys. Costs for infills and partitions, have been evaluated based on a list of refurbishment activities and depending on the Damage State (DS) of the infill panel only. DSs were defined according to the European Macroseismic scale (Grunthal 1998), from DS1 
to DS3 (namely, for DSs involving damage to infills according to EMS-98). Additionally, this work proposes a relationship between repair costs and the so-called "mean damage" (including damage level and extension), given the achieved maximum damage state, which allows significantly reducing the dispersion in loss prediction, along with a trend of repair cost with the number of stories.

Thanks to the post-earthquake in-situ surveys after L'Aquila (Italy) 2009 earthquake, the loss prediction methodology has been first validated by means of the comparison with actual repair costs related to specific case-study buildings. The mean predicted-to-actual total repair costs ratio for these buildings results very close to the unity.

Lastly, a large-scale level validation of the methodology is carried out by analysing a wide dataset of (about 2500) RC buildings, mainly resulting damaged to infills and partitions with very slight or null damage to structural components. Actual repair costs for this building stock were obtained from previous studies from the literature about the topic (Dolce and Manfredi 2015; Di Ludovico et al. 2017a, b). It was observed that the actual costs are well predicted by the presented methodology.

The application of the procedure showed promising results for seismic loss estimation of infilled residential RC buildings typical of the Mediterranean area. However, a further research effort should be addressed towards the integration of the described methodology with repair costs related to structural members for a comprehensive assessment of seismic losses, especially for higher damage level. An additional future extension of the presented procedure will be devoted to considering also the variability of unit costs, which can be different from those adopted herein, depending, for example, on the geographic area or on the market laws.

Acknowledgements This work was developed under the support of AXA Research Fund Post-Doctoral Grant (E67G17000020007) "Advanced nonlinear modelling and performance assessment of masonry infills in RC buildings under seismic loads: the way forward to design or retrofitting strategies and reduction of losses", ReLUIS-DPC 2019-2021 funded by the Italian Department of Civil Protection (DPC) and PONAIM Ricerca e Innovazione 2014-2020-Fondo Sociale Europeo, Azione I.2 "Smart, Secure and Inclusive Communities". These supports are gratefully acknowledged.

Funding Open access funding provided by Università degli Studi di Napoli Federico II within the CRUICARE Agreement.

Open Access This article is licensed under a Creative Commons Attribution 4.0 International License, which permits use, sharing, adaptation, distribution and reproduction in any medium or format, as long as you give appropriate credit to the original author(s) and the source, provide a link to the Creative Commons licence, and indicate if changes were made. The images or other third party material in this article are included in the article's Creative Commons licence, unless indicated otherwise in a credit line to the material. If material is not included in the article's Creative Commons licence and your intended use is not permitted by statutory regulation or exceeds the permitted use, you will need to obtain permission directly from the copyright holder. To view a copy of this licence, visit http://creativecommons.org/licenses/by/4.0/.

\section{References}

Adhikari R, Gautam D (2019) Component level seismic fragility functions and damage probability matrices for Nepali school buildings. Soil Dyn Earthq Eng 120:316-319

Ahmad N, Crowley H, Pinho R (2010) Analytical fragility functions for reinforced concrete and masonry buildings and building aggregates-UPAV-internal report

Aslani H, Miranda E (2005) Probabilistic earthquake loss estimation and loss disaggregation in buildings. J. A. Blume Earthquake Engineering Center. Research report n. 157. Stanford, California, United States

ATC - Applied Technology Council (2012a) FEMA P-58 next-generation seismic performance assessment for buildings, vol 1-methodology. Federal Emergency Management Agency, Washington 
ATC - Applied Technology Council (2012b) FEMA P-58 next-generation seismic performance assessment for buildings, vol 1-implementation. Federal Emergency Management Agency, Washington

Baggio C, Bernardini A, Colozza R, Coppari S, Corazza L, Della Bella M, Di Pasquale G, Dolce M, Goretti A, Martinelli A, Orsini G, Papa F, Zuccaro G (2007) Field manual for post-earthquake damage and safety assessment and short-term countermeasures. Translation from Italian: Goretti A, Rota M, JRC Scientific and Technical Reports, EUR 22868 EN-2007

Bal IE, Crowley H, Pinho R (2008) Displacement-based earthquake loss assessment for an earthquake scenario in Istanbul. J Earthq Eng 12(S2):12-22

Boore DM (1997) Estimates of average spectral amplitudes at FOAKE sites, Appendix C in an evaluation of methodology for seismic qualification of equipment, cable trays, and ducts in ALWR Plants by use of experience data. In: Bandyopadhyay KK, Kana DD, Kennedy RP, Schiff AJ (eds) U.S. Nuclear Regulatory Commission NUREG/CR-6464 and Brookhaven National Lab BNL-NUREG- 52500, C-1-C-69

Borzi B, Pinho R, Crowley H (2008) Simplified pushover-based vulnerability analysis for large scale assessment of RC buildings. Eng Struct 30(3):804-820

Bramerini F, Di Pasquale G, Orsini G, Pugliese A, Romeo RW, Sabetta F (1995) Rischio sismico del territorio italiano. In: Proceedings 7th national conference on earthquake engineering in Italy, Siena, September 1995, vol 3, pp 1099-1108

B.U.R.A. (Official Journal of Regione Abruzzo) (n. 10—08/03/2017—ordinary) (2017) Price list of public works in Abruzzi Region, Italy (in Italian)

Cardone D (2016) Fragility curves and loss functions for RC structural components with smooth rebars. Earthq Struct 10(5):1181-1212

Cardone D, Perrone G (2015) Developing fragility curves and loss functions for masonry infill walls. Earthq Struct 9(1):257-279

CEN 2004 (2004) Eurocode 8: design of structures for earthquake resistance_part 1: general rules, seismic actions and rules for buildings. European Committee for Standardization, Ref. N. EN 1998-1

Chang SE, Shinozuka M (1996) Life-cycle cost analysis with natural hazard risk. J Infrastruct Syst 2(3):118-126

Chioccarelli E, De Luca F, Iervolino I (2009) Preliminary study of L'Aquila earthquake ground motion records V5. 20. ReLuis report. http://www.reluis.it

Colonna E, Molina C, Petrini V (1994) Criteri di valutazione della vulnerabilità sismica del patrimonio edilizio esistente sul territorio nazionale. Ingegneria Sismica, no 1, Gen-Apr 1994

Cosenza E, Del Vecchio C, Di Ludovico M, Dolce M, Moroni C, Prota A, Renzi E (2018) The Italian guidelines for seismic risk classification of constructions: technical principles and validation. Bull Earthq Eng 16(12):5905-5935

Crowley H, Pinho R, Bommer JJ (2004) A probabilistic displacement-based vulnerability assessment procedure for earthquake loss estimation. Bull Earthq Eng 2:173-219

Crowley H, Stafford PJ, Bommer JJ (2008) Can earthquake loss models be validated using field observations? J Earthq Eng 12(7):1078-1104

De Luca F, Verderame GM, Gomez-Martinez F, Perez-Garcia A (2014) The structural role played by masonry infills on RC buildings performances after the 2011 Lorca, Spain, earthquake. Bull Earthq Eng 12(5):1999-2026

De Martino G, Di Ludovico M, Prota A, Moroni C, Manfredi G, Dolce M (2017) Estimation of repair costs for RC and masonry residential buildings based on damage data collected by post-earthquake visual inspection. Bull Earthq Eng 15:1681-1706

De Risi MT, Del Gaudio C, Verderame GM (2019) Evaluation of repair costs for masonry infills in rc buildings from observed damage data: the case-study of the 2009 L'Aquila earthquake. Buildings 9(5): 122

Del Gaudio C, Ricci P, Verderame GM, Manfredi G (2016) Observed and predicted earthquake damage scenarios: the case study of Pettino (L'Aquila) after the 6th April 2009 event. Bull Earthq Eng. https://doi.org/10.1007/s10518-016-9919-2

Del Gaudio C, Ricci P, Verderame GM, Manfredi G (2017) Urban-scale seismic fragility assessment of RC buildings subjected to L'Aquila earthquake. Soil Dyn Earthq Eng 96:49-63

Del Gaudio C, Rosti A, Rota M, Ricci P, Penna A, Verderame GM (2019a) Derivazione di curve di fragilità empiriche per edifici residenziali in c.a.. Atti del XVIII Convegno Nazionale in Ingegneria Sismica ANIDIS. Settembre 15-19, Ascoli Piceno, Italia

Del Gaudio MT, De Risi C, Ricci P, Verderame GM (2019b) Empirical drift-fragility functions and loss estimation for infills in reinforced concrete frames under seismic loading. Bull Earthq Eng. https:// doi.org/10.1007/s10518-018-0501-y 
Del Vecchio C, Di Ludovico M, Pampanin S, Prota A (2018) Repair costs of existing RC buildings damaged by the L'Aquila earthquake and comparison with FEMA P-58 predictions. Earthq Spectra 34(1):237-263

Del Vecchio C, Di Ludovico M, Prota A (2019) Repair costs of RC building components: from actual data analysis to calibrated consequence functions. Earthq Spectra 36(1):353-377

Di Ludovico M, Prota A, Moroni C, Manfredi G, Dolce M (2017a) Reconstruction process of damaged residential buildings outside historical centres after the L'Aquila earthquake: part II- "heavy damage" reconstruction. Bull Earthq Eng 15(2):693-729

Di Ludovico M, Prota A, Moroni C, Manfredi G, Dolce M (2017b) Reconstruction process of damaged residential buildings outside historical centres after the L'Aquila earthquake: part I- " light damage" reconstruction. Bull Earthq Eng 15(2):667-692

Di Pasquale G, Orsini G (1998) A probabilistic model for the assessment of the earthquake economic losses in Italy. In: Proceedings international conference 'risk analysis 98', Valencia, Spain

Di Pasquale G, Orsini G, Romeo RW (2005) New developments in seismic risk assessment in Italy. Bull Earthq Eng 3(1):101-128

D.M. (2008) Norme tecniche per le costruzioni (NTC 2008) - D.M. 14/1/08 (in Italian)

D.M. (2018) Aggiornamento delle «Norme Tecniche per le Costruzioni »- D.M. 17/1/18 (in Italian)

Dolce M, Goretti A (2015) Building damage assessment after the 2009 Abruzzi earthquake. Bull Earthq Eng 13(8):2241-2264

Dolce M, Manfredi G (2015) Libro bianco sulla ricostruzione privata fuori dai centri storici nei comuni colpiti dal sisma dell'Abruzzo del 6 aprile 2009. Doppiavoce Editore, Napoli (in Italian)

Dolce M, Speranza E, Giordano F, Borzi B, Bocchi F, Conte C, Di Meo A, Faravelli M, Pascale V (2019a) Observed damage database of past Italian earthquakes: the Da. DO WebGIS. Bollettino di Geofisica Teorica ed Applicata 60(2):141-164

Dolce M, Borzi B, da Porto F, Faravelli M, Lagomarsino S, Magenes G, Moroni C, Penna A, Prota A, Speranza E, Zuccaro G, Verderame GM (2019b) Mappe di rischio sismico per il territorio italiano. XVIII Convegno ANIDIS 2019 "L'ingegneria sismica in Italia" (Ascoli Piceno, 15 settembre-19 settembre 2019)

FEMA (2003) HAZUS-MH technical manual. Federal Emergency Management Agency, Washington

Furtado A, De Risi MT (2020) Recent findings and open issues concerning the seismic behaviour of masonry infill walls in RC buildings. Adv Civ Eng 2020, Article ID 9261716. https://doi. org/10.1155/2020/9261716

Gautam D, Chaulagain H (2016) Structural performance and associated lessons to be learned from world earthquakes in Nepal after 25 April 2015 (MW 7.8) Gorkha earthquake. Eng Fail Anal 68:222-243

Gautam D, Fabbrocino G, de Magistris FS (2018) Derive empirical fragility functions for Nepali residential buildings. Eng Struct 171:617-628

Grunthal G (1998) Cahiers du Centre Europeen de Geodynamique et de Seismologie: volume 15-European Macroseismic Scale 1998. European Center for Geodynamics and Seismology, Luxembourg

Guagenti E, Molina C, Mulas G (1988) Seismic risk analysis with predictable models. Earthq Eng Struct Dyn 16:343-359

Health Ministery Decree of 5 July 1975. Amendments to the ministerial instructions of 20 June 1896, related to the minimum interstorey height and to the health and hygiene requirements of dwellings. G.U. n. 190 of 18 July 1975 (in Italian)

Jalayer F, Asprone D, Prota A, Manfredi G (2011) Multi-hazard upgrade decision making for critical infrastructure based on life-cycle cost criteria. Earthq Eng Struct Dyn 40(10):1163-1179

Kang YJ, Wen YK (2000) Minimum life-cycle cost structural design against natural hazards. University of Illinois Engineering Experiment Station, College of Engineering, University of Illinois at Urbana-Champaign, Champaign

Li Y, Dong Y, Frangopol DM, Gautam D (2020) Long-term resilience and loss assessment of highway bridges under multiple natural hazards. Struct Infrastruct Eng 16(4):626-641

Michelini A, Faenza L, Lauciani V, Malagnini L (2008) ShakeMap implementation in Italy. Seismol Res Lett 79(5):688-697

O'Reilly GJ, Sullivan TJ (2018) Probabilistic seismic assessment and retrofit considerations for Italian RC frame buildings. Bull Earthq Eng 16(3):1447-1485

OPCM 3778 6/06/2009 (2009) Ulteriori interventi urgenti diretti a fronteggiare gli eventi sismici verificatesi nella regione Abruzzo il giorno 6 aprile 2009 e altre disposizioni urgenti di protezione civile, Gazzetta Ufficiale n. 132 del 10 giugno (in Italian)

Pagni CA, Lowes LN (2006) Fragility functions for older reinforced concrete beam-column joints. Earthq Spectra 22(1):215-238 
Perrone G, Cardone D, O'Reilly GJ, Sullivan TJ (2019) Developing a direct approach for estimating expected annual losses of Italian buildings. J Earthq Eng. https://doi.org/10.1080/13632 469.2019.1657988

Ramirez CM (2009) Building-specific loss estimation methods \& tools for simplified performance-based earthquake engineering. Stanford University, Stanford

Ricci P, De Luca F, Verderame GM (2011) 6th April 2009 L'Aquila earthquake, Italy: reinforced concrete building performance. Bull Earthq Eng 9(1):285-305

Rossetto T, Elnashai A (2003) Derivation of vulnerability functions for European-type RC structures based on observational data. Eng Struct 25(10):1241-1263

Rosti A, Del Gaudio C, Rota M, Ricci P, Penna A, Verderame GM (2019a) Uso di curve di fragilità empiriche per la valutazione del rischio sismico a scala nazionale. XVIII Convegno ANIDIS 2019 "L'ingegneria sismica in Italia" (Ascoli Piceno, 15 settembre-19 settembre 2019)

Rosti A, Rota M, Magenes G, Penna A (2019b) Derivazione di curve di fragilità empiriche per edifici residenziali in muratura. Atti del XVIII Convegno Nazionale in Ingegneria Sismica ANIDIS. Settembre 15-19, Ascoli Piceno, Italia

Ruiz-Pinilla JG, Adam JM, Pérez-Cárcel R, Yuste J, Moragues JJ (2016) Learning from RC building structures damaged by the earthquake in Lorca, Spain, in 2011. Eng Fail Anal 68:76-86

Sassun K, Sullivan TJ, Morandi P, Cardone D (2016) Characterising the in-plane seismic performance of infill masonry. Bull N Zeal Soc Earthq Eng 49(1):100-117

Silva V, Amo-Oduro D, Calderon A, Dabbeek J, Despotaki V, Martins L, Rao A, Simionato M, Viganò D, Yepes C, Acevedo A, Horspool N, Crowley H, Jaiswal K, Journeay M, Pittore M (2018) Global earthquake model (GEM) seismic risk map (version 2018.1). https://doi.org/10.13117/GEMGLOBAL-SEISMIC-RISK-MAP-2018.1

Spence R (ed) (2007) Earthquake disaster scenario predictions and loss modelling for urban areas. LESSLOSS Report 7, IUSS Press, Pavia, Italy. Sullivan and Calvi (2011)

Stratta JL, National Research Council (1981) Earthquake in Campania-Basilicata, Italy, November 23, 1980: a reconnaissance report. National Academies

Sullivan TJ, Calvi GM (2011) Considerations for the seismic assessment of buildings using the direct displacement-based assessment approach. In: Proceedings of the 2011 ANIDIS conference, Bari 2011

Taghavi S, Miranda E (2003) Response assessment of nonstructural building elements, PEER report 2003/05. The Pacific Earthquake Engineering

Welch DP, Sullivan TJ, Calvi GM (2014) Developing direct displacement-based procedures for simplified loss assessment in performance-based earthquake engineering. J Earthq Eng 18(2):290-322

Yang WS, Slejko D, Viezzoli D (1989) Seismic risk in Friuli-Venezia Giulia: an approach. Soil Dyn Earthq Eng 8(2):96-105

Publisher's Note Springer Nature remains neutral with regard to jurisdictional claims in published maps and institutional affiliations. 